\title{
Da ciência descontextualizada à ciência no contexto social e histórico
}

\section{From Decontextualized Science to Social and Historical Context}

\author{
JAMES McGUIRE \\ Universidade de Pittsburgh, EUA \\ BARBARA TUCHANSKA \\ Universidade de Lodz, Polônia
}

\begin{abstract}
RESUMO Nossa discussão sobre concepções filosóficas da ciência não significa que tenhamos o objetivo de oferecer outro quadro sinóptico da filosofia da ciência contemporânea. A nossa intenção é mostrar que, em sua evolução interna, a filosofia da ciência seguiu da descontextualização, da decomposição e da essencialização para perspectivas menos idealizadas da ciência, as quais levam em consideração sua natureza social e histórica. Ao enfatizar a natureza purificada e idealizada das abordagens iniciais na filosofia da ciência anglo-americana, não temos o intuito de depreciá-las. Optamos por uma maneira de combiná-las, o que pode levar ao"entendimento contextual". Esta é uma compreensão filosófica da ciência enquanto um elemento essencial da forma de vida em que habita o filósofo. Esse fato existencial inevitável, participando de certo modo, presente aqui e agora, a forma de vida, é uma fonte de aspecto situacional indispensável de qualquer descrição e avaliação científica ou filosófica.
\end{abstract}

Palavras-chave filosofia da ciência no século XX - empirismo lógico - mudança científica - globalismo entendimento contextual.

\begin{abstract}
Our discussion of philosophical conceptions of science does not mean that we aim to give another synoptic picture of contemporary philosophy of science. It is our intention to show that, in its internal evolution, the philosophy of science proceeded from decontextualization, decomposition and essentializing, toward less idealized views of science which consider its social and historical nature. In stressing the purifying and idealizing nature of the initial approaches in the Anglo-American philosophy of science we do not intend to be pejorative. Purification purposively omitted those aspects of science which were considered to be unimportant, secondary, or inessential, and concentrated on what was assumed to be constitutive of science itself. We opt for a way of combining them together, which can lead to "contextual understanding". It is a philosophical understanding of science as an essential element of the form of life in which the philosopher dwells. This unavoidable existential fact participating in a certain, here and now present, form of life is a source of the indispensable situational aspect of any scientific or philosophical description and evaluation.
\end{abstract}

Key words philosophy of science at the 20th century - logical empiricism - scientific change-globalism-contextual understanding. 


\section{Introdução}

Na filosofia e na história da ciência existem duas formas de se abordar a ciência. Essas interpelações podem ser caracterizadas como análogas à visão de Ludwig Wittgenstein sobre as possibilidades de acesso relativas à linguagem. A primeira, que pode ser chamada de epistemológica (racionalista, essencialista), pergunta: o que é a ciência? A segunda se ocupa com o modo como a ciência funciona. ${ }^{1} 0$ empirismo lógico e as metodologias, como as de Karl Popper, são exemplos da primeira abordagem, enquanto a segunda é encontrada na sociologia e na história da ciência, bem como em certas concepções filosóficas recentes.

A primeira abordagem descontextualiza a ciência, a separa de seu contexto socio-histórico real. Além disso, a decompõe de tal maneira que a complexa totalidade social e histórica da ciência é reduzida a uma visão pré-concebida do que seja o conhecimento científico e de como se dá o seu desenvolvimento. A razão para a descontextualização é simples: seja lá o que a ciência for, assim o é por si mesma. 0 motivo para a decomposição também é óbvio: somente a análise revela a estrutura essencial e fundamental da ciência. Essa perspectiva sobre a ciência é objetivista, primordialmente sincrônica, e se concentra nos produtos da prática científica. Ao levar em conta os participantes da prática científica, ela oferece "uma imagem do conhecedor humano desligado do contexto e situado em um mundo objetivo, cuja natureza difere da natureza do conhecedor". ${ }^{2}$ A ciência é essencializada por meio de esforços para destemporalizar sua temporalidade, reduzindo a mudança científica à imposição de critérios universais de comparação de teorias. ${ }^{3}$

A segunda abordagem observa a ciência a partir do contexto sócio-histórico. Consoante essa perspectiva, vivemos em mundos culturais que são artefatos contingentes de nossa livre criação; não há verdades atemporais, nem um método científico, baseado na razão, que permita soluções corretas para todos os problemas genuínos em todos os campos de investigação científica. Aliás, essa visão é "diacrônica e leva a sério a temporalidade e a historicidade incorporadas na realização da mudança científica". ${ }^{4}$

No entanto, os praticantes dessa abordagem estão inclinados a reduzir a ciência ao contexto social, isto é, a considerá-la como nada mais do que um sistema de relações sociais, ou práticas sociais, ou unidades de poder etc. Consequentemente, quaisquer ponderações filosóficas relativas à questões ontológicas, tais como a gênese e a natureza da ciência, permanecem ocultas por trás das descrições a respeito do funcionamento da ciência.

A oposição que estamos descrevendo é, sem dúvida, uma simplificação exagerada, que não apenas desconsidera as diferenças internas e as transformações históricas de ambas as perspectivas, mas também deixa de notar que, nos dois lados, existem concepções filosóficas, sociológicas, antropológicas e históricas. Em consequência, todas as diferenças entre essas concepções são ignoradas. Nosso objetivo é substituir essa dicotomia entre as abordagens essencialista e histórica por uma imagem mais fecunda.

A imagem da ciência elaborada pela filosofia contemporânea anglo-americana não é de modo algum uma visão simples e internamente coerente, tampouco é aceita de maneira unânime por todos os seu proponentes. É uma pletora de posições variadas que passaram por muitas modificações significativas. Não foram apenas as unidades de análise adotadas pelos filósofos que mudaram, mas também o modo como elas têm sido usadas e os tipos de perguntas colocadas. Conforme Richard Bernstein enfatiza corretamente, referindo-se à primeira questão:

(...) testemunhamos uma dialética interna que passou da preocupação (virtualmente uma obsessão) com o termo individual isolado, para a sentença ou à proposição, para o esquema ou quadro conceitual, para uma contínua tradição histórica constituída por práticas sociais; um movimento do atomismo lógico para a dinâmica continuidade histórica. ${ }^{5}$

Essa transição é o movimento da visão individualista, analítica e, em certo sentido, fundacionalista acerca do conhecimento científico para uma abordagem holística. Foi acompanhada pela mudança de uma visão sincrônica da ciência para uma visão diacrônica, ou seja, dos problemas da estrutura lógica das expressões científicas e suas relações lógicas, para o problema da transformação científica. Uma característica importante dessa transição é a troca 
das análises lógicas por várias reconstruções metodológicas da prática científica, e, depois, por imagens naturalistas, biológicas ou sociológicas do desenvolvimento da ciência. ${ }^{6}$

Examinando as três transições, podemos distinguir, seguindo Bernstein, quatro estágios no desenvolvimento da filosofia da ciência no século XX:

$\left.1^{\circ}\right)$ Inaugurado pela filosofia analítica e continuado pelo empirismo lógico, foi inicialmente marcado por uma abordagem reducionista, logicista e fundacionalista. Tentou-se encontrar as unidades básicas últimas da linguagem científica que pudessem ser analisadas em termos lógicos. "Isto se refletiu na preocupação com a 'definição ostensiva' e nas tentativas altamente artificiais de se isolar 'nomes lógicos adequados'". 7

$2^{\circ}$ ) Conduzido pelos empiristas lógicos e positivistas lógicos, ainda era caracterizado pelas atitudes reducionista, logicista e fundacionalista, mas iniciou uma substituição da proposição enquanto unidade epistemológica primária para fundar o conhecimento empírico. "Isso desencadeou a busca por um critério de sentido cognitivo que distinguiria, de uma vez por todas, as proposições empiricamente significativas daquelas que são meramente exibidas como proposições cognitivamente significativas, mas que não se enquadram em um 'rigoroso' critério de significado empírico". ${ }^{8}$ Em consequência, a concentração sobre a significação [meaningfulness] e a natureza empírica da ciência tornaram-se as questões centrais que abrangiam o problema de como enunciados teóricos estão conectados com a experiência.

$\left.3^{\circ}\right)$ Deslocou 0 interesse da linguagem da ciência para a sua prática. Em geral, a prática era considerada como uma atividade cognitiva que produzia conhecimento científico, de acordo com regras metodológicas, e uma reconstrução racional dos procedimentos da ciência se tornou o objeto principal das análises filosóficas, permanecendo fundacionalista em espírito.

$\left.4^{0}\right)$ Marcado, em certo sentido, por um retorno ao estudo das estruturas objetivas do conhecimento, e é uma perspectiva sócio-histórica e holística. Esta é caracterizada pela crescente percepção de que, quando se trata de questões interessantes sobre a racionalidade da investigação científica, temos que nos concentrar no conflito de teorias, paradigmas, programas de pesquisa e tradições de pesquisa em seus desenvolvimentos históricos. ${ }^{9}$

Nossa discussão sobre concepções filosóficas da ciência (e.g., empirismo lógico, metodologias e as mais atuais visões "globalistas" da ciência ${ }^{10}$ ) não significa que tenhamos o objetivo de oferecer outro quadro sinóptico da filosofia da ciência contemporânea. ${ }^{11}$ Pelo contrário, a nossa intenção é mostrar que, em sua evolução interna, a filosofia da ciência seguiu da descontextualização, da decomposição e da essencialização para perspectivas menos idealizadas da ciência, as quais levam em consideração sua natureza social e histórica. Ao enfatizar a natureza purificada e idealizada das abordagens iniciais na filosofia da ciência anglo-americana, não temos o intuito de depreciá-las. A purificação omitiu, propositalmente, aqueles aspectos da ciência que foram considerados como sendo irrelevantes, secundários ou não essenciais, e concentrou-se sobre o que era aceito como constitutivo da ciência em si mesma. Ainda assim, abordagens idealizadas foram capazes de elaborar e elucidar certas características da ciência. Curiosamente, a reação crítica à abordagem idealizada aponta a necessidade de se reconstituir o que relegaram como não sendo essencial. Como resultado, tanto os esforços dos purificadores quanto de seus críticos aprofundaram e ampliaram nosso conhecimento da ciência. Agora, esse conhecimento requer integração e síntese.

\section{A ciência descontextualizada e decomposta}

Em certo sentido, o empirismo lógico (neopositivismo) embarcou no programa fundacionalista da epistemologia tradicional, compartilhando de seus ideais de certeza e de suas crenças em elementos epistemológicos privilegiados. ${ }^{12}$ Ele também adotou o ideal tradicional de que a tarefa da epistemologia é justificar o conhecimento (científico), quer dizer, fornecer-Ihe garantias epistemológicas. Conforme Rudolf Carnap confessou em sua Autobiografia Intelectual, ele - assim como seus colegas do Círculo de Viena, com exceção de Otto Neurath - acreditava que a tarefa da filosofia 
consistia em reduzir todo conhecimento a uma base de certeza. ${ }^{13} \mathrm{~A}$ análise lógica da ciência é, portanto, universalista e normativa em seus objetivos. Isso não proporciona uma descrição de como teorias particulares são estruturadas, ou de como são formuladas na ciência real. De mais a mais, os empiristas lógicos descontextualizam a ciência; eles não a estudam de modo factual, ou melhor, enquanto um fenômeno histórico e social pertencente à cultura e influenciado por outras esferas da vida social.

A ciência descontextualizada é moldada por uma atitude logicista emprestada da filosofia analítica. Isso levou os empiristas lógicos a uma purificação extrema da ciência. Eles trataram o conhecimento científico como nada mais do que um sistema de expressões linguísticas; a estrutura e as conexões podem ser reveladas pela análise lógica. A vigorosa postura antimetafísica e antipsicológica do empirismo lógico é o pano de fundo para a afirmação de que, sendo a filosofia purificada de todos os elementos não científicos, somente a lógica da ciência permanece. ${ }^{14}$ Os empiristas lógicos, de fato, acreditavam que todos os problemas relativos à ciência eram sintáticos. ${ }^{15} 0$ conhecimento científico é, por conseguinte, interpretado de modo puramente linguístico, isto é, como um conjunto de termos e sentenças conectados por relações lógicas, e não como sendo composto de conceitos, ideias e juízos. ${ }^{16}$ Dessa forma, 0 empirismo lógico decompôs o conhecimento científico em elementos mais ou menos autônomos. Presumia-se que a análise lógica (reconstrução, explicação) das teorias científicas revelasse e elucidasse a natureza conceitual ou estrutural destas. ${ }^{17}$ Logo, a abordagem neopositivista da análise é essencialista: revela o que está oculto, velado e disfarçado. ${ }^{18}$ Além de tudo, elabora filosofias que estão fora do tempo e da história.

0 conhecimento, decomposto pela análise e descrito em termos linguísticos, não era, contudo, interpretado como um sistema logicamente unificado de sentenças equivalentes. 0 conhecimento empírico foi tomado como tendo uma base, uma pedra de sustentação, constituída pelo conhecimento do imediatamente dado, ou seja, os dados dos sentidos. Suposto estava que todo tipo de conhecimento fosse firmemente apoiado nessa base e que, outrossim, pudesse ser decidido com certeza. ${ }^{19}$

Pensava-se que o conhecimento dos dados dos sentidos fosse indubitável, enquanto o de coisas materiais fora concebido como derivado e carente de suporte epistêmico. ${ }^{20} 0$ conhecimento, reconstruído dessa forma e ordenado em uma hierarquia baseada na experiência, é objetivo em dois sentidos:

Primeiro, a linguagem básica da ciência dirige-se ao tribunal da experiência observacional imediata, que se acredita ser intersubjetivamente acessível a todos os observadores imparciais. Ademais, o sonho da 'visão recebida' é capturar linguisticamente essa experiência em sua forma mais pura através de um vocabulário mínimo que distorce a experiência o mínimo possível. Segundo, é objetivo no sentido de que a linguagem básica é a linguagem da lógica moderna, uma linguagem empregada para simular as estruturas da realidade exterior. ${ }^{21}$

A distinção observacional-teórica, incorporada nessa hierarquia, é uma das ideias mais duramente criticadas do empirismo lógico. As críticas avançadas por Hans Reichenbach, Popper, Willard Quine, Hilary Putnam, Paul Feyerabend, Norwood Hanson, Bas van Fraassen e muitos outros expuseram sua natureza artificial e, finalmente, a relegaram ao esquecimento. ${ }^{22}$

Segundo nosso ponto de vista, a crítica de Quine é de particular importância, porque ataca a fundação sobre a qual repousa a decomposição do conhecimento científico. Ele argumenta que, se as dicotomias analítico-sintéticas e observacional-teóricas não podem ser estabelecidas de modo convincente, não há qualquer razão que nos obrigue a não conceber a ciência como um corpo de conhecimento que tem uma dependência dupla em relação à linguagem e à experiência, e que, como um todo, não seja uma "unidade de significância empírica". A ciência é "um tecido criado pelo homem que incide sobre a experiência somente ao longo das bordas; é como um campo de força com leis lógicas no centro e enunciados observacionais na periferia". ${ }^{23}$

Entretanto, mesmo na imagem holística de Quine, o conhecimento científico permanece sincrônico e descontextualizado. Ele percebe, decerto, que o saber científico não pode ser visto como dependente da linguagem e da experiência sem reconhecer que é humanamente construído. Não obstante, ele continua enxergando o conhecimento como um 
todo desencarnado, abstraído da prática, e expresso monoliticamente na teoria, a qual, para ele, é a única forma de conhecimento científico. Porém, o entendimento não é monolítico, inteiramente articulado e flexível à axiomatização. Analisando Michael Polanyi, filósofos reconheceram na ciência a presença do conhecimento tácito, que é inarticulado, pessoal, integrado às hábeis performances dos cientistas enquanto familiaridade com ferramentas [conceituais e técnicas], e que é aprendido mediante exemplo. ${ }^{24}$ Tais estruturas cognitivas implícitas funcionam como um quadro interpretativo e moldam tanto a linguagem abstrata quanto 0 trabalho no laboratório. ${ }^{25}$

Não é a imagem holística do conhecimento proposta por Quine que constitui os fundamentos da rejeição da perspectiva descontextualizada do conhecimento científico, mas, sim, um movimento da filosofia da linguagem do último Wittgenstein. Se a linguagem não é um sistema objetivo autossuficiente, mas existe nos jogos de linguagem dos seres humanos, então a redução do conhecimento científico às expressões linguísticas não pode despojá-lo de sua natureza social e histórica.

Outra crítica importante dirigida contra a descontextualização do conhecimento científico vem daqueles que entendem a filosofia da ciência como "metodologia da ciência". Eles examinaram uma suposição tácita do empirismo lógico, a saber, a crença de que a estrutura lógica das teorias científicas, e especialmente a relação entre seus vocabulários empírico e teórico, era a questão mais relevante para a filosofia da ciência. Ainda que os empiristas lógicos não admitissem que essa crença fosse central para sua posição, sua prática está de acordo com isso: eles tratam as teorias científicas como estruturas objetivas e desencarnadas, independentes de seu contexto constituído pela atividade dos cientistas. Consequentemente, os metodologistas mudaram a questão central da filosofia da ciência de lugar; eles abandonaram o problema da estrutura dos enunciados científicos e suas conexões lógicas e avançaram 0 problema das regras metodológicas que regem a cognição científica. Concentrando-se na prática dos cientistas, eles recuperaram o contexto pragmático (interno) do conhecimento científico.

A abordagem pragmática (metodológica) da ciência (quer dizer, do conhecimento científico) ${ }^{26}$ é marcada pela separação entre racionalidade e lógica. ${ }^{27}$ De fato, os filósofos começaram a se concentrar nas regras metodológicas da ciência. Isso os levou a relacionar com mais proximidade o conhecimento científico às várias ações cognitivas desempenhadas pelos cientistas. 0 que os empiristas lógicos chamavam de "sentenças teóricas", tornou-se "teorias", "hipóteses", "conjecturas", "explicações", etc. Na maioria das concepções metodológicas, todavia, o conceito de racionalidade continuou intimamente ligado ao conceito de logicidade [logicality] ${ }^{28}$ Nesses casos, 0 critério para julgar a racionalidade dos procedimentos científicos continua sendo relativo a características formais, tais como a coerência, a implicação, o conteúdo (lógico) e a verdade. Outra marca da forma de transição de uma visão logicista da ciência para uma visão pragmática foi o reconhecimento de que a construção de teorias científicas é uma questão de escolha razoável, e não de submissão aos fatos brutos.

0 fato de os metodologistas restaurarem o contexto pragmático do conhecimento científico e se referirem aos atos cognitivos dos cientistas, tais como aprovação, rejeição e preferência, etc., não significa que sua visão de ciência não seja descontextualizada, purificada e idealizada. ${ }^{29}$ Uma das oposições básicas que caracteriza a abordagem metodológica da ciência é a distinção entre o contexto da descoberta e o contexto da justificação, introduzida por Hans Reichenbach em 1938. Essa oposição permite relegar os problemas relativos à descoberta científica à psicologia, à sociologia e à história da ciência. A filosofia da ciência permanece um estudo puramente epistemológico do contexto da justificação, e sua questão central torna-se o problema da análise das regras de aceitação ou de preferência racionais por proposições (teóricas), teorias inteiras, e mesmo por sistemas mais abrangentes (tais como os programas de pesquisa). Sem dúvida, as mais notáveis propostas representativas da abordagem metodológica são a lógica da descoberta científica de Popper e a metodologia dos programas de pesquisa de Imre Lakatos.

Popper não propõe um modelo lógico da linguagem da ciência ou uma metodologia naturalista, ou melhor, um estudo empírico dos procedimentos reais da ciência. ${ }^{30}$ Ele elabora uma metodologia racionalista crítica, a qual tomou como 0 núcleo da justificação do conhecimento científico. A partir dessa perspectiva, a ciência empírica não é simplesmente um sistema de teorias, mas uma prática cognitiva. Uma parte dessa prática, a saber, o teste de hipóteses científicas, 
demanda análise lógica, isto é, uma reconstrução racional de seu método. ${ }^{31}$ Na concepção de Popper, a ciência é um tipo de jogo, e os testes teóricos e empíricos contêm atos de decisão envolvendo consensos e convicções. No entanto, a característica mais essencial desses testes é o fato de serem guiados por regras metodológicas. ${ }^{32}$ Essa crença é uma fonte da normatividade e da universalidade na metodologia popperiana.

Consoante Lakatos, a filosofia da ciência proporciona metodologias normativas, e sua própria metodologia estabelece regras para a apreciação de programas de pesquisa. ${ }^{33}$ Esta é uma teoria da racionalidade científica que é tanto descritiva quanto normativa, no sentido de que oferece um programa de pesquisa (historiográfico) para reconstrução racional de episódios provenientes da história da ciência. Isso permite ao filósofo interpretar tais episódios de um modo puramente interno, como casos de aplicação das regras da razão. Todas as referências aos fatores psicológicos e sociológicos envolvendo cientistas reais são da alçada da história da ciência externa, empírica e suplementar.

Os metodologistas não querem contar estórias [stories] sobre a pesquisa real. Pelo contrário, eles tratam tais pesquisas como correlativos purificados de regras metodológicas: um cientista é um sujeito que segue as regras do Método da ciência. ${ }^{34} \mathrm{~A}$ posição de Popper é a purificação racionalista em sua forma mais clarificada: seu objetivo é a epistemologia sem um sujeito conhecedor.

A reconstrução racional não é somente uma idealização da ciência; ela é normativa, porque deriva "regras para desempenhar bem o jogo científico" . ${ }^{35}$ Sob a ótica de Popper, a meta global da ciência é composta por verossimilhança e ampliação do conteúdo explanatório. Lakatos enfatiza que os jogos [games] científicos não relacionados à verossimilhança teriam sido "um conjunto de despreocupadas apostas céticas perseguidas para fins de diversão intelectual", e não um "empreendimento falibilista de aproximação da Verdade sobre o Universo" ${ }^{36}$ Portanto, a verossimilhança é 0 critério (principal) para as avaliações racionais dos cientistas a respeito das teorias e das escolhas teóricas. 0 conceito de (maior) verossimilhança, ou seja, semelhança à verdade ou proximidade com a verdade é, diz Popper, uma noção lógica. Isso combina a noção de verdade e o conceito de conteúdo (lógico) de um enunciado, e é introduzido para explicar a afirmação intuitiva de que chegamos mais próximo da verdade. ${ }^{37}$ Essa afirmação subjaz como um princípio regulativo (mesmo que meramente de modo inconsciente e intuitivo) à racionalidade de todas as discussões científicas críticas. ${ }^{38}$

Ao optarem por uma abordagem idealizada, normativa e fundacionalista da ciência, os metodologistas preservam um ideal epistemológico cartesiano. Como Bernstein corretamente explicita:

\begin{abstract}
(...) a busca por um algoritmo para a escolha de teoria, ou por um critério claro e explícito para demarcar a ciência da não-ciência, ou para reconstruir os padrões permanentes que se acredita que devem reger a validação de hipóteses e teorias científicas, são legados do cartesianismo na filosofia analítica contemporânea da ciência. Eles refletem a exigência de que o filósofo da ciência está apto a enunciar critérios e padrões explícitos, determinados e fixos. A tarefa do filósofo da ciência é oferecer uma reconstrução racional da ciência que irá, clara e inequivocamente, especificar esses procedimentos, critérios e padrões de decisão. ${ }^{39}$
\end{abstract}

Sem dúvida, Bernstein está certo em apontar a presença do fundacionalismo no tipo de metodologia racionalista representada por Popper, embora aparente o contrário.

Não está claro se a teoria do método científico de Popper é, como ele mesmo declara, uma filosofia da ciência não falseável ou se é corroborada pela história da ciência. ${ }^{40}$ Todavia, não há dúvidas de que ele adota uma atitude crítica não apenas no que se refere à ciência, mas também no que diz respeito à sua própria posição, e que "ele não pode resistir à tentação de fortalecer suas prescrições com argumentos baseados na história dos sucessos científicos". ${ }^{41}$ Os seguidores de Popper respondem à vulnerabilidade de sua posição de duas formas diferentes. Alguns deles, tais como Feyerabend e Lakatos, afirmam que aquela é falseada pela história da ciência. ${ }^{42}$ Outros creem que a noção de verossimilhança justifique racionalmente as declarações normativas da metodologia de Popper porque fornece à ciência um critério objetivo para toda estimativa científica. A verossimilhança das teorias é independente das preferências subjetivas dos cientistas e, decerto, de toda influência histórica local. Isso garante a racionalidade última das avaliações científicas: 
diante de duas teorias concorrentes, os cientistas se comportam racionalmente e sempre escolhem aquela que está mais próxima da verdade. Porém, o conceito de verossimilhança não é satisfatório mesmo para os seus partidários. A despeito de todas as tentativas explanatórias, ainda não é uma noção técnica clara que poderia garantir a objetividade, mas apenas um tipo de postulado normativo. ${ }^{43}$

A tentativa dos metodologistas de purificar a prática científica, para essencializá-la e encontrar as fundações últimas que justifiquem "o jogo bem jogado da ciência", está manifesta em seu conceito de racionalidade científica. Embora não haja muitas questões na filosofia da ciência contemporânea mais carregadas de dissensão do que o problema da racionalidade científica, muito frequentemente é usada para se remeter à ação dos cientistas, especialmente às suas decisões a respeito da aceitação ou rejeição de teorias, hipóteses ou orientações de pesquisa. A importância do conceito de racionalidade decorre de duas fontes mutuamente conectadas: a ameaça do relativismo e a "ansiedade cartesiana". A descoberta de que na ciência há casos de desacordo, ou mesmo de falta de comunicação, aumenta a ansiedade de se isso possa, em princípio, ser solucionado racionalmente. ${ }^{44}$ Se não [puder], a ciência é ameaçada pelo relativismo, e a filosofia da ciência torna-se nada mais do que sociologia ou história da ciência. É por isso que a busca pelo núcleo racional da ciência é tão crucial para muitos filósofos.

No entendimento dos filósofos, as regras das ações racionais são especificadas pela metodologia, ${ }^{45}$ e, nesse sentido, a racionalidade da ciência é uma função de seu método. ${ }^{46} \mathrm{~A}$ metodologia pode ser, entretanto, um empreendimento puramente descritivo. Para Larry Laudan, que aceita essa posição, estabelecer quais ações são propícias para fins específicos é uma questão empírica. ${ }^{47}$ Ademais, Laudan insiste que não apenas os meios para fins preferidos deveriam ser estabelecidos empiricamente, mas metas cognitivas também precisariam ser decididas em acordo com valores implícitos na prática científica comunal. ${ }^{48}$ Deste modo, ele naturaliza ambos os elementos presentes nas descrições da racionalidade científica que ele corretamente distingue, quer dizer, a metodologia e a axiologia. ${ }^{49}$

Uma tentativa de naturalizar o componente axiológico depara-se com críticas severas daqueles que optam pela "racionalidade científica" ${ }^{50}$ Eles acreditam que 0 elemento axiológico da concepção filosófica de racionalidade científica pode (e deve) ser estabelecido como um resultado do raciocínio puramente epistemológico, o qual irá subscrever os padrões universais de racionalidade.$^{51}$ Os neopositivistas incorporam os elementos axiológicos em seus critérios de demarcação que atribuem valor epistêmico às teorias científicas bem confirmadas. $E$, em conformidade com sua abordagem completa, eles tentam justificar seus padrões de racionalidade por meio da elaboração de uma teoria da estrutura lógica da confirmação. Os metodologistas, que andam à sombra de Popper, encaram a verossimilhança como a meta intuitivamente óbvia da ciência e aceitam isso enquanto o valor epistêmico maior, embora, talvez, não 0 único. ${ }^{52}$ Outros, como William Newton-Smith, Stephen Toulmin, and Harvey Siegel, tentam encontrar um caminho intermediário entre axiologias dogmáticas e relativistas. ${ }^{53}$ Eles procuram por uma base ontológica ou epistêmica para o elemento axiológico da racionalidade científica, a qual, para eles, não é absoluta nem puramente local. Eles apontam traços invariantes da cognição humana, ou apelam para características constitutivas pertencentes à própria ciência, ou enraízam a racionalidade na sobrevivência biológica, ou acentuam a necessidade de postular a existência de certos objetos naturais que são reconhecidos em todas as culturas humanas. ${ }^{54}$

A recente "virada naturalista" da filosofia da ciência conduziu à postura mais radicalmente antidogmática do abandono de questões normativas relativas à racionalidade e à justificação. Muitos autores (Polanyi, Feyerabend, Kuhn, Quine, Ronald Giere, Hilary Putnam, lan Hacking, Richard Rorty, Bernstein) declaram que podemos somente descrever os métodos usados por cientistas e rejeitam a possibilidade de construir uma metodologia prescritiva normativa. ${ }^{55}$ Inicialmente, eles concordavam que a racionalidade científica é prática e abrange um amplo espectro de racionalidades locais e historicamente variáveis típicas de paradigmas ou tradições intelectuais diferentes. ${ }^{56}$

A diferença entre a posição relativista e a intermediária [the middle-way position] é a seguinte. Os relativistas aceitam a ideia de que padrões de objetividade científica são construídos pela atividade histórica e comunal dos cientistas e eles não exigem quaisquer explicações ou justificações adicionais. Os partidários do caminho intermediário apelam para universais externos, os quais eles tomam como sendo a-históricos, de modo a evitar o relativismo. 
A visão de Feyerabend é particularmente perspicaz ${ }^{57}$. Opondo-se ao modo de Popper objetivar o componente metodológico da ciência, Feyerabend subsume isso à concepção idealista da relação entre razão e prática. A oposição ao idealismo é o naturalismo, de acordo com o qual a razão é completamente determinada pela prática: "A razão recebe tanto 0 seu conteúdo quanto a sua autoridade da prática. Isso descreve o modo como a prática trabalha e formula seus princípios subjacentes" ${ }^{58} 0$ idealismo e o naturalismo são ambos insatisfatórios para Feyerabend porque perdem o fato de que "a razão e a prática não são dois tipos diferentes de entidades que podem existir separadamente, mas partes de um mesmo processo dialético". ${ }^{59}$ Observando Wittgenstein, Feyerabend afirma que "padrões e regras não são independentes do material sobre o qual atuamos", ${ }^{60}$ e os trata como dois lados da prática (científica): "Eu considero toda ação e toda parte da pesquisa como uma instância potencial da aplicação de regras e como um teste de caso" ${ }^{61}$ A ação pode violar as regras existentes e mudá-las, a perseverança na obediência às regras pode mudar a prática. As regras metodológicas que operam na pesquisa científica não podem ser objetivadas separando-as da ação real e tratando-as como anteriores a esta. Elas estão implantadas nas tradições científicas, nos juízos de valor feitos pelos cientistas, e em suas ações. No entender de Feyerabend, regras metodológicas e, portanto, racionalidades científicas estão implantadas nas tradições científicas. ${ }^{62}$ Esta é uma imagem holística e "dialética" da relação entre razão e práticas.

As concepções metodológicas da ciência combinam análises epistemológicas (logicista ou metodológica) com uma visão empírica da ciência enquanto uma prática realizada pelos cientistas, cujas interpretações subjetivas, preferências e convenções compartilhadas influenciam escolhas racionais. E depois, parece que elas não podem evitar referências à natureza social do jogo científico. Em consequência, a separação entre o contexto da justificação e do contexto da descoberta não é preservada, e, por isso, é impossível haver metodologia científica livre de todos os componentes factuais.

0 fato de que o componente factual (subjetivo ou convencional) não possa ser eliminado da imagem metodológica da ciência é o motivo dessa abordagem encarar um dilema que é, conforme já mostramos, intensamente discutido por muitos de seus proponentes. É um dilema entre absolutismo e relativismo.

0 absolutismo (ou idealismo) estabelece padrões a priori do que seja científico ou racional, pretende desconsiderar ou minimizar a importância dos componentes factuais e históricos do método da ciência, e considera os cientistas como sujeitos cognitivos ideais e plenamente racionais.

Por outro lado, o relativismo histórico-social é uma posição que leva, consoante seus críticos, ao niilismo e ao derrotismo. ${ }^{63}$ Os relativistas estão prontos para conduzir os padrões do empreendimento científico segundo a direção da autoridade relativa e transitória de algum grupo de referência local. ${ }^{64}$ Eles enfatizam, como faz Feyerabend ao referirse a Protágoras, o pluralismo das tradições e dos valores.$^{65} 0$ relativismo é, portanto, inaceitável para os absolutistas, tais como os metodologistas que acreditam em um conjunto a-histórico e universalmente válido de regras do Método científico e, assim, de racionalidade científica. 0 relativismo é extremo demais para aquele que busca, como Toulmin, Newton-Smith, ou Siegel, uma posição intermediária entre absolutismo e relativismo.

\section{A redescoberta do social}

A abordagem holística ou globalista encarrega-se da tarefa de reconstituir o aspecto comunitário da ciência, abandona o logicismo e o ideal de reconstruir a ciência racionalmente para torná-la compatível com um programa metodológico. Em vez de constituir a lógica da ciência, os globalistas têm por objetivo entender a atividade científica real, e não a idealização desta. Do ponto de vista globalista, a concentração "sobre questões lógicas da justificação distorce as perspectivas sobre a dinâmica de desenvolvimento do empreendimento científico e negligencia o contexto mais amplo no qual a ciência cresce e se transforma". ${ }^{66}$ A tentativa globalista para compreender a ciência como um fenômeno psicossocial e histórico real resulta em uma rejeição quase unânime das dicotomias constitutivas das abordagens idealizadas anteriores: teoria vs observação; contexto da justificação vs contexto da descoberta, fatos vs valores, história interna vs história externa. ${ }^{67}$ 
De uma perspectiva globalista, a cognição científica não é um exemplo idealizado do método científico objetivo e historicamente universal, do qual as regras podem ser inteiramente reconstruídas. Kuhn enfatiza que "a existência de um paradigma não precisa sequer implicar que exista qualquer conjunto completo de regras", ${ }^{68}$ e, acompanhando Michael Polanyi, localiza os protocolos da pesquisa científica na esfera do conhecimento tácito. Os globalistas falam sobre a prática da ciência, seus procedimentos e protocolos, sua retórica, seus valores e padrões, os compromissos e as decisões dos cientistas, etc., e não sobre métodos abstratos e não factuais da ciência, nem sobre as estruturas que estes geram. Os globalistas introduzem conceitos adicionais ou substituem os antigos, de modo a entender a maneira como diferentes elementos da ciência atuam nas comunidades científicas; ${ }^{69}$ eles procuram por fatores que afetam a cognição científica em condições psicológicas e sociológicas. 0 mais radical dos globalistas acredita que "a busca por condições necessárias e suficientes ou regras para a escolha de teorias é um projeto fadado ao fracasso" . ${ }^{70}$ Kuhn acentua, por exemplo, que a ciência normal é uma atividade altamente determinada que não precisa ser inteiramente condicionada por regras. Em consequência, ele substitui a regulação por meio do método da ciência pela determinação de paradigmas compartilhados..$^{71} \mathrm{~A}$ busca do globalista pelas condições e circunstâncias psicossociais é, com certeza, inaceitável para os partidários da filosofia racionalista da ciência. Segundo eles, a referência às condições factuais não ajuda a filosofia da ciência, porque esta tem de descobrir razões que são independentes dos estados mentais e das comunidades científicas. Se tais razões não existem, a filosofia da ciência é impossível.

Uma importante e clara manifestação do deslocamento para essa nova filosofia da ciência é a concepção de que a ciência é um empreendimento carregado de valores. 0 conceito de valor substitui os conceitos de regras lógicas e metodológicas, formalmente cogitadas para garantir o caráter algorítmico e quase mecânico dos procedimentos científicos. ${ }^{72}$ Esse movimento tem seus antecedentes nos pragmatistas, tais como Charles Sanders Pierce e Clarence Irving Lewis, que acentuam o papel dos valores na promoção dos sempre mutáveis objetivos da ciência e enfatizam a estreita ligação entre valores e cognição. ${ }^{73}$

Uma reconsideração do papel constitutivo que os valores desempenham na prática científica começa com o artigo de Richard Rudner, publicado em 1953, ${ }^{74}$ e é encontrada em escritores como Feyerabend, Toulmin, Laudan, McMullin, Kuhn, Nicholas Rescher, e Shapere. Fora, na verdade, Popper quem antecipou a importância dos valores nas escolhas científicas em suas considerações acerca do papel essencial que a tomada de decisão tem na ciência. ${ }^{75}$ Contudo, é nós trabalhos de Kuhn, McMullin, e Rescher que se encontram a vigorosa afirmação de que toda a prática científica é carregada de valores. ${ }^{76}$ Dessa perspectiva, como Rescher acentua, a ciência deve ser compreendida enquanto uma praxis regida por valores, uma vez que o empreendimento cognitivo do conhecimento científico e o empreendimento de apreciação da avaliação racional não são conflitantes, mas complementares. ${ }^{77}$

A substituição dos conceitos de regras e padrões metodológicos pelo conceito de valor é o resultado do abandono de um dos pilares do neopositivismo, a saber, o ideal de justificacionismo. Se a metodologia não pode oferecer justificação para os métodos científicos ou às suas regras, ela deveria apelar para as considerações dos valores, aos quais a noção de justificação epistêmica não se aplica diretamente porque são factuais, no sentido de que são (geralmente) propriedades objetivas desejáveis do conhecimento científico. ${ }^{78}$ Logo, se a filosofia da ciência aceita a indeterminação das teorias, ela deve evocar valores integrais para todos os procedimentos na ciência, de modo a preencher a lacuna entre as teorias e a evidência. ${ }^{79}$ Finalmente, evocar valores (sejam epistêmicos, sejam não epistêmicos, por exemplo, pragmáticos, éticos, políticos) nos permite tratar as decisões científicas de um modo mais realista e, em certo sentido, socializar e historicizar o epistêmico. Os valores que emergiram gradualmente por intermédio da prática científica não determinam escolhas (como se supôs que as regras metodológicas o fizessem), eles as influenciam. ${ }^{80}$ Por causa deles, as escolhas científicas são baseadas em juízos de valor abertos à discussão, e não apenas em gostos subjetivos.

A descrição da prática científica, à luz dos valores, não é necessariamente a aceitação do relativismo; tanto Kuhn quanto McMullin enfatizam que os valores científicos não são completamente históricos, e que há razões para confiar nos valores presentes na ciência contemporânea. ${ }^{81}$

Umas das razões para chamar essa nova tendência da filosofia da ciência anglo-americana de "globalismo" é a adoção quase unânime da ideia de uma tradição intelectual: uma perspectiva conceitual, um paradigma, um programa 
de pesquisa, um ideal científico, etc., dentro da qual a ciência é feita, e que forma uma Weltanschauung ["visão de mundo"] para as comunidades científicas que nela trabalham. ${ }^{82}$ Tais totalidades cognitivas e históricas determinam em que questões valem a pena investir, quais tipos de respostas são legítimas, como projetar experimentos e que critérios devem ser aplicados na avaliação dos dados e das teorias, etc. As regras para interpretar os dados, bem como para construir e avaliar teorias são consideradas como limitadas historicamente. Ademais, essas totalidades comunais não apenas constituem um contexto social para os cientistas que nelas trabalham, ou que as criticam e as rejeitam; elas determinam a relação entre conhecimento científico e a realidade estudada pela ciência. Não há regras universais de correspondência entre enunciados teóricos e os fenômenos; as aplicações das teorias são por estas predeterminadas. ${ }^{83}$

Em consequência, tradições intelectuais condicionam, de certo modo, o mundo em que o cientista executa suas pesquisas. Essa ideia é salientada por Kuhn e Feyerabend. Quando Kuhn considera a essência das revoluções científicas, ele enfatiza que o mundo científico não é fixado de uma vez por todas pela natureza do ambiente, de um lado, e pela da ciência, de outro. Pelo contrário, isso é determinado conjuntamente pelo ambiente e pela particular tradição científica normal em que 0 estudante foi treinado a seguir. ${ }^{84}$ Feyerabend vai ainda mais longe. Ele rejeita a separação entre 0 mundo e o conhecimento científico implementada pelos realistas científicos e trata as entidades científicas como projeções. De acordo com Feyerabend, tais entidades:

(...) não são encontradas, e não constituem um estágio "objetivo" para todas as culturas e para toda a história. Elas são moldadas por grupos, culturas, civilizações especiais; e são moldadas de um material que, dependendo de seu tratamento, nos proporciona deuses, espíritos, uma natureza que é companheira dos humanos mais do que um laboratório para seus experimentos, ou nos mune com quarks, campos, moléculas, placas tectônicas. ${ }^{85}$

Os globalistas socializam tanto o conhecimento científico quanto a atividade científica ao localizá-los em totalidades comunais. Eles são radicalmente históricos e geralmente antifundacionalistas. Eles tratam a ciência como uma sequência histórica consistindo em estruturas suprateóricas limitadas e práticas locais conectadas àquelas. Para eles, a tarefa da filosofia da ciência não pode ser projetada de modo fundacionista, porque a filosofia da ciência não pode revelar elementos epistemológicos privilegiados, nem oferecer justificação lógica ou metodológica para os procedimentos científicos.

Tendo rejeitado uma crença essencialista na estrutura lógica universal da ciência e uma crença igualmente essencialista no Método da ciência, a filosofia da ciência globalista permanece, em sua maior parte, normativa, embora em um sentido modificado. Ela não emite diretamente uma questão normativa de como a ciência deve ser feita. Busca, antes, uma imagem nomológica da ciência, ou melhor, uma descrição e explicação ou racionalização universal da atividade científica em seus contextos variáveis. Sua atitude antifundacional revela-se, conforme veremos a baixo, na substituição das perspectivas epistemológicas, isto é, logicistas ou puramente metodológicas do desenvolvimento científico, por imagens naturalistas.

A filosofia da ciência globalista pode ser encarada, portanto, como uma contribuição para a morte da epistemologia cartesiana ou, sendo mais preciso, da crença cartesiana no conhecimento certo e objetivo, e da certeza de que seus fundamentos podem ser descobertos e expressos em regras universais da razão.

\section{Explicação científica revisitada: a virada para o concreto}

0 modelo de lei de cobertura da explicação de Carl Hempel e Paul Oppenheim ${ }^{86}$ dominou a filosofia da ciência por muitas décadas. A principal ideia reza que explicar um efeito é deduzir descrições canônicas daquele a partir de generalizações legiformes e descrições das condições iniciais. Em outras palavras, os fenômenos são subsumidos a leis 
que podem ser de escopo ou universal, ou probabilístico. Os fenômenos foram assumidos como sendo não complexos e determinados, em última análise, por leis físicas pertencentes unicamente à entidades fundamentais, uma concepção assumida para assegurar que a unidade da ciência fosse protegida. Durante a maior parte do século XX, o interesse filosófico no status das leis e a alegação de que somente regularidades legiformes explicam era, para dizer o mínimo, uma obsessão. Atualmente, há uma tendência geral de se questionar se tais coisas, como as leis, desempenham algum papel crucial na atividade científica real. Muitos aspectos do modelo hempeliano têm sido tão severamente criticados que, agora, sua adequação é colocada em dúvida. Uma importante contribuição para essa crítica vem do campo da filosofia da biologia, agora em florescimento.

Um aspecto essencial do modelo de lei de cobertura tornado problemático dentro desse campo é o próprio conceito de regularidades naturais sem exceções. 0 notável aqui é o "pluralismo integrativo" [integrative pluralism] de Sandra Mitchell. ${ }^{87}$ Ela não deixa lugar para a essencialização e a decomposição filosófica, as quais podem levar a um privilégio da redução a entidades fundamentais. 0 objetivo de seu trabalho é capturar a complexidade evolutiva, multicomponente e de variados níveis dos sistemas biológicos. Ela argumenta que o "pluralismo integrativo" é a melhor descrição das complexidades dos fenômenos e processos estudados pelas ciências biológicas, especialmente os diferentes e complexos processos - históricos e interativos - que geram aqueles fenômenos.

Mitchell vê nas ciências biológicas esquemas explicativos diferentes, cada um investido de várias capacidades explicativas e ainda atuando de modo que possa ser estabelecida a coerência ou a integração funcional entre o grupo. Em resumo, pode haver integração teórica, ela afirma, sem o recurso às visões mais tradicionais da unidade da ciência.

Outra crítica substancial do modelo de lei de cobertura da explicação vem daqueles que rejeitam a ideia de que seja suficiente para a filosofia da ciência estudar a estrutura lógica das explicações científicas. Eles discutem ou a causalidade, ou o papel dos mecanismos.

Aqueles que trabalham com a noção de causação física, entre eles Wesley Salmon e Philip Dowe, estão desencantados com a visão tradicional humana, da regularidade da causação e enfatizam a noção de agência causal e a capacidade produtiva de interações causais. Na opinião de Salmon e Dowe, efeitos causais devem ser entendidos em termos de transferências causais dentro de um sistema físico. No caso de Salmon, processos causais transmitem uma "marca", e é uma "marca de transmissão" que estabelece o critério para distinguir processos causais de processos não causais. ${ }^{\text { j }}$ No entendimento Dowe, que trabalha a partir dos estudos científicos, quantidades conservadas são os transmissores e os portadores dos verdadeiros efeitos causais. ${ }^{89}$

Para Peter Machamer, Lindley Darden e Carl Craver, o que vem à tona é a noção de que efeitos deveriam ser entendidos como resultados das operações dos mecanismos. Segundo eles, um mecanismo consiste em "entidades e atividades organizadas de tal modo que são geradoras de mudanças naturais iniciais ou que estabelecem as condições de finalização", e ainda: tais condições-limite são marcadas pela produção do efeito de interesse. ${ }^{90}$ Os mecanismos são por eles concebidos enquanto a atividade interconectada de vários tipos de entidades. Machamer, Darden, and Craver não são ontologicamente comprometidos: entidades podem se enquadrar em várias categorias ônticas, incluindo objetos particulares, características dos objetos, eventos, processos e estados. Explicações mecanicistas respondem questões específicas sobre o modo como os mecanismos operam.

Ao contrário dos empiristas lógicos, os quais sustentam que explicar um evento é deduzir suas descrições a partir de generalizações legiformes e as descrições de suas condições iniciais, os mecanicistas acreditam que a explicação provém de uma descrição detalhada dos trabalhos das entidades relevantes. Isso introduz uma hóstia de novas questões sobre como mecanismos são individualizados, que tipos de continuidades se mantêm entre as atividades de suas entidades componentes, como entender a noção de atividade produtiva, e que tipos de regularidades factuais e contrafactuais são requeridas por suas operações.

Manifestamente, explicar as coisas em termos de mecanismos é examinar como a ciência funciona em seus contextos específicos e concretos. A explicação a partir da abordagem do mecanismo evita purificações abstratas 
e decomposições draconianas em entidades privilegiadas. Cada mecanismo é considerado em seu próprio conjunto individual e descreve como este realmente se move desde o início até o fim. Explicação por descrição é o resultado da narração das atividades das entidades que compõem um dado mecanismo. No reino dos mecanismos, o efeito é tudo, e a meta é mostrar que tipos de efeitos são produzidos e como são produzidos.

Uma resposta anti-humana da produtividade causal é desenvolvida por James Bogen. ${ }^{91}$ Ele parte da visão de Elizabeth Anscombe de que os termos "causação", "causar" e "atividade produtiva" são indexadores abstratos, vazios e precisam ser preenchidos por considerações que se referem a entidades específicas causalmente produtoras, tais como "raspagem" [scraping], "rolar" [rolling over], "permanência" [keeping off], "ligado quimicamente" [chemically binding], "atraído eletricamente" [electrically attracting], "sinalização neuronal" [neuronically signaling], etc. Sua questão é: o que distingue o causal do não causal ou as ocorrências coincidentes na natureza? Ao responder, ele critica a visão filosófica padrão que busca condições necessárias e suficientes que irão capturar em todo caso 0 que é causalmente operativo em qualquer episódio causal. Em vez disso, ele desenvolve a consideração anscombiana segundo a qual, se um dado fator fez uma contribuição causal para a produção de um dado efeito, isso depende de fatos específicos, contingentes e empiricamente determináveis, levando-se em conta como as coisas se comportam em contextos particulares e o que resulta daquele comportamento. Assim, o critério para o que conta como uma consequência causalmente produtiva irá variar muito de caso a caso e de um contexto para outro, e não é preciso assumir que a causalidade seja entendida de modo informativo apenas em termos de regularidades contrafactuais reais.

As abordagens sobre a ciência a partir dos pontos dos mecanismos, da causação física, do estabelecimento de critérios caso a caso da produção causal, e da visão integrativa do pluralismo explanatório, direciona-as às realidades da prática científica. Elas são exemplos de uma crescente tendência em direção à rejeição da centralidade das generalizações legiformes na ciência e formam parte de um maior desenvolvimento na filosofia da ciência durante os últimos vinte anos ou mais, que abrange o abandono da explicação científica pela não excepcionalidade das leis naturais e a própria ideia de unidade da ciência. Como resultado, há uma contínua reavaliação do papel desempenhado pela generalidade na explicação científica.

\section{A domesticação da experiência científica}

0 modo descontextualizado e purificado de se considerar a ciência na filosofia da ciência anglo-americana também afetou sua visão sobre a experiência científica. 0 empirismo tradicional afirma que as ideias provêm das impressões da experiência. Os empiristas também sustentam que o sentido de todo conhecimento significativo deriva da experiência, e mais: que todos os enunciados significativos são julgados verdadeiros ou falsos, aceitáveis ou inaceitáveis, unicamente por meio da referência à experiência. ${ }^{92} \mathrm{Os} \mathrm{neopositivistas,} \mathrm{decerto,} \mathrm{rejeitam} \mathrm{as} \mathrm{conotações} \mathrm{psicologistas} \mathrm{e} \mathrm{mentalistas}$ de conceitos como "ideia" ou "impressão", e tratam a experiência científica de uma maneira puramente linguística. Isso Ihes permite estreitar o vínculo entre sentido e experiência, bem como estabelecer uma demarcação entre sentenças científicas e metafísicas. Eles acreditam que essa maneira de entender a experiência científica não apenas elimina 0 psicologismo, mas também descarta os aspectos não essenciais e pragmáticos da observação científica, e, assim, revela as bases objetivas da ciência. ${ }^{93}$

No núcleo de seu empirismo está a suposição de uma fronteira entre as linguagens teórica e observacional, e, inicialmente, a ideia de que o sentido dos termos teóricos é total e exclusivamente proporcionado por sua redução mediante cadeias introdutórias de termos observacionais. Presume-se que certos termos da linguagem científica denotam a experiência imediata, outros termos são concebidos como passíveis de serem introduzidos por intermédio de definições lógicas formais. Ambas, as linguagens e a linha divisória entre elas, são descontextualizadas: consideradas como universais e independentes de quaisquer circunstâncias psicológicas e sociais. 
A purificação linguística da experiência científica tem importantes consequências filosóficas, reconhecidas (com aprovação) mesmo pelos partidários dessa posição. Tal purificação elimina quaisquer considerações ontológicas da filosofia da ciência:

Segundo essa perspectiva, o mundo externo é qualquer coisa que satisfaça essas construções lógicas, e a estrutura das definições garante aquilo que satisfaz as construções, de algum modo, devem ser conjuntos de experiências imediatas, ou conjuntos de conjunto de conjuntos de experiência imediata e assim por diante. Deste modo, qualquer conversa inteligivel sobre objetos da ciência, o mundo exterior, ou qualquer outra coisa, é reduzida a uma conversa sobre experiências possíveis. ${ }^{94}$

Os neopositivistas consideram a experiência sensorial como fundamental não apenas para o sentido e a aceitabilidade de uma teoria em particular, mas também para a comparação de diferentes teorias. É imperativo que eles se refiram a um único estoque de enunciados observacionais. ${ }^{95} \mathrm{~A}$ concepção de conhecimento científico estabelecido pelos empiristas lógicos é, por consequência, profundamente fundacionista. Termos e sentenças observacionais constituem suas bases infalíveis. Presume-se que a relação entre estas e a experiência sensível seja direta e não mediada:96 logo, todas as outras sentenças são derivativas.

Entretanto, o programa fundacional neopositivista falhou. Eles foram forçados a admitir que as regras de correspondência proporcionavam termos teóricos apenas com interpretação indireta e imparcial. Em outras palavras, tiveram de admitir que o sentido empírico dos termos teóricos era acompanhado por seus sentidos não observacionais independentes. Outrossim, como Putnam argumentou, mesmo que haja diferença entre entidades referidas por termos teóricos e observacionais, isso não é apreendido pela versão neopositivista da distinção observacional-teórica. Em primeiro lugar, ao contrário do que é afirmado, termos teóricos se referem a entidades observacionais. Em segundo lugar, enunciados de observação frequentemente contêm termos teóricos, e estes não podem ser compreendidos somente em referência a coisas observáveis. ${ }^{97}$

Quine provocou danos devastadores na crença logicista na existência das bases empíricas naturais da ciência, existência esta que é a fonte tanto dos dados quanto dos significados. A crítica de Quine (1953) ao dogma reducionista do empirismo e à teoria da verificação do sentido enfraqueceu o projeto de redução do teórico ao observacional, e, finalmente, levou à tese da subdeterminação das teorias científicas. Quine substituiu a teoria da verificação do sentido por sua concepção holística do sentido, de acordo com a qual as sentenças têm sentido somente enquanto partes de teorias e, enfim, do sistema total da ciência. 0 controle empírico dos enunciados também não é individual, mas holístico: "Nossos enunciados sobre o mundo externo enfrentam o tribunal da experiência sensível não individualmente, mas apenas enquanto um corpo unificado". ${ }^{88}$ Em consequência, a verificação perde seu papel crucial: é sempre possível neutralizar os efeitos das alterações no valor de verdade de uma sentença no corpo do conhecimento como um todo fazendo-se ajustes alhures. ${ }^{99}$ Além disso, se não há critérios de significação [meaningfulness] transcendentalmente válidos, nem qualquer razão convincente para comparar todas as asserções de sentido com o que é empiricamente determinável, então os significados devem ser tratados como parte do discurso (científico) e o critério de significação deve ser encarado como baseado na concordância entre os participantes do discurso. ${ }^{100}$

A queda da crença na linguagem observacional universal e a aceitação da tese da subdeterminação contribuíram para a substituição da versão logicista de empirismo por um amplo espectro de perspectivas sobre a natureza empírica da ciência, perspectivas que estão baseadas na rejeição de uma determinação estrita, direta e coerciva dos fatos empíricos sobre o conhecimento científico.

Nas concepções metodológicas, a experiência é tratada como um caso muito mais complicado, contendo decisões e acordos comuns ${ }^{101}$, e, consequentemente, valores. ${ }^{102}$ Desse modo, uma caracterização da observação científica enquanto recepção passiva de estímulos e registro de dados empíricos foi substituída pela visão de que aquela tem uma natureza construtiva, porque é sempre carregada de teoria [theory-laden]. Os filósofos jogaram fora a crença na pureza e na posição privilegiada da evidência. ${ }^{103}$ Filósofos perceberam que, como Michael Polanyi notou sensatamente, na 
natureza as coisas não trazem o rótulo de "evidência", mas são evidências apenas na medida em que são aceitas como tais por nós enquanto observadores. ${ }^{104} \mathrm{Em}$ consequência, nas ciências naturais, estudadas a partir de uma perspectiva contemporânea, os dados não são separáveis da teoria. As teorias determinam a maneira como os fatos são vistos: as relações legiformes declaradas sobre a experiência são internas, no sentido de que conta como fato aquilo que é constituído pelo que a teoria diz a respeito de suas inter-relações mútuas. Aliás, a linguagem das ciências naturais é irredutivelmente metafórica e inexata, e os significados são determinados pelas teorias e suas relações. ${ }^{105}$

0 passo final foi executado pelos antiempiristas radicais que baniram por completo da ciência a dicotomia teórico-observacional. Lakatos diz que todas as proposições da ciência são teóricas. ${ }^{106}$ Logo, na ciência, as teorias não se chocam com os fatos; só pode haver choque entre teorias, a saber: "[entre] uma teoria interpretativa que fornece os fatos e a teoria explanatória que os explica". ${ }^{107}$ Ademais, se, na ciência, a experiência não é mais fundamental do que a teoria, e não é necessária para testar toda teoria independentemente, então, argumenta Lakatos, a teorização pode proceder por si mesma. Portanto, disciplinas teóricas são relativamente autônomas e solucionam problemas gerados por suas próprias práticas, por exemplo, aquelas oriundas de dificuldades matemáticas. ${ }^{108}$ Feyerabend afirma que todos os fatos são teóricos, ou seja, os termos observacionais não são meramente carregados de teorias, mas integralmente teóricos. ${ }^{109}$ Essa afirmação revela com clareza o radicalismo de sua posição antiempirista. Se os fatos não existem sem interpretações, todas as entidades, as quais a ciência se refere, são projeções de teorias científicas. Elas estão "atadas à teoria, à ideologia, à cultura que as postulam e projetam". ${ }^{110}$

As concepções contemporâneas de experiência científica não apenas reconhecem o caráter profundo e inevitavelmente teórico desta: o nexo entre observação e manipulação, juntamente com o uso de equipamento tecnológico, [também] tem sido reconhecido. A observação não mais está separada da prática. Os filósofos perceberam que objetos do conhecimento são afetados pelo seu processo de aquisição. ${ }^{111}$

Opondo-se à visão da ciência dominada pela teoria, lan Hacking chamou a atenção para a prática experimental. Observação, mensuração e experimentação são habilidades constitutivas da atividade relativamente autônoma da prática científica. A relação entre experimentação e teorização é historicamente mutável, embora a primeira tenha vida própria. Esta não precisa ser formada por teorias ou ser realizada com o fito de testar teorias. ${ }^{112}$ Não é uma prática para descoberta de fenômenos, quer dizer, eventos publicamente discerníveis ou processos que ocorrem regularmente sob circunstâncias definidas, mas uma prática de produção, refinamento e estabilização. ${ }^{113} 0$ que constitui o núcleo dos experimentos científicos é a intervenção, a manipulação e o uso de entidades (não observáveis):

Experimentar é criar, produzir, refinar e estabilizar os fenômenos. Se estes fossem abundantes na natureza... Seria notável se os experimentos não funcionassem. Mas os fenômenos são difíceis de produzir de qualquer maneira estável. É por isso que eu falo em criar, e não meramente em descobrir os fenômenos. ${ }^{114}$

Hacking e outros filósofos elaboraram uma perspectiva histórica holística sobre teorias, realidades e tecnologias. ${ }^{115}$ Estas são reciprocamente relacionadas em complexos históricos condicionados por práticas técnicas e sociais. ${ }^{116}$ As tecnologias fazem a medição entre teorias e realidades, trocando entidades teóricas por coisas concretas, ou melhor, retificando entidades teóricas e idealizando realidades. ${ }^{117}$ A relação entre instrumentos e realidades não é, contudo, direta; é mediada, em seu turno, por teorias que são as fontes da justificação dos resultados instrumentais e de mensuração. ${ }^{118}$ Finalmente, a relação entre tecnologias e teorias é mediada pelas realidades, porque, sem a intervenção destas, a aplicação da tecnologia não poderia servir ao propósito do teste empírico. Em geral, como Kuhn enfatiza em seus comentários sobre o estudo de Wise, cada um desses três elementos é constitutivo para os outros dois, e todos eles são necessários para a produção de conhecimento. ${ }^{119}$

A natureza manipuladora da prática instrumental oferece, nas palavras de Hacking, a mais forte evidência para 0 realismo científico. As entidades que são usadas para produzir outros fenômenos são tratadas de maneira realista pelos experimentadores. Em outras palavras, os cientistas (experimentadores) não precisam tratar de maneira realista as entidades (teóricas) que investigam até que comecem a usá-las, a manipulá-las. ${ }^{120}$ Esse modo de entender o realismo 
científico, isto é, enquanto uma atitude que os cientistas tomam em relação às coisas que manipulam, não contradiz uma perspectiva filosófica da ciência enquanto uma prática construtiva:

Os cientistas, equipados com um organismo complexo e estabelecidos em ambientes físicos e sociais em constante modificação, usaram ideias e ações (e, mais tarde, equipamentos, incluindo complexos industriais tais como CERN) para manufaturar, em primeiro lugar, átomos metafísicos, em segundo, átomos físicos brutos, e, finalmente, sistemas complexos de partículas elementares que não contêm esses elementos, mas que poderiam ser moldados a partir deles. De acordo com essa explanação, os cientistas são escultores da realidade, mas escultores em um sentido especial. Eles não apenas agem causalmente sobre o mundo [...] eles também criam as condições semânticas gerando fortes inferências de efeitos conhecidos a novas previsões e, reciprocamente, de projeções a efeitos testáveis. ${ }^{121}$

\section{Essencializando a mudança científica}

Os modelos existentes de desenvolvimento científico (modelos de redução teórica, de mudança teórica, de progresso cognitivo ou de desenvolvimento da ciência) podem ser divididos em dois grupos principais: epistemológicos (logicista ou racionalista) e naturalistas, que apelam ora para conceitos psicossociais, ora para conceitos biológicos (evolucionistas). As concepções neopositivistas de redução teórica, o modelo popperiano do crescimento do conhecimento objetivo e a concepção de história interna de Lakatos pertencem ao primeiro grupo; os modelos de Kuhn, Laudan, Toulmin, David Hull ou Ronald Giere, ao segundo. ${ }^{122}$ Muitos desses modelos, principalmente aqueles pertencentes ao primeiro tipo, revelam tendências já mencionadas da filosofia da ciência contemporânea: purificação, descontextualização e decomposição.

0 empirismo lógico não tratou a ciência diacronicamente, embora tivesse à sua disposição os recursos teóricos para considerar as relações históricas entre as teorias científicas. Do seu ponto de vista, comparar teorias significa, basicamente, reconstruir a relação lógica que as une e mostrar que uma teoria é uma consequência lógica de outra. A partir dessa perspectiva, por exemplo, a teoria newtoniana é tratada como derivável da [teoria] einsteiniana. ${ }^{123}$

Porém, essa visão tornou-se insatisfatória mesmo para os seus adeptos. Eles tiveram de reconhecer que a relação de uma teoria mais abrangente com uma menos abrangente não poderia ser analisada de forma adequada em termos estritamente lógicos referindo-se apenas à sintaxe. Assim, começaram a considerar as conexões dentre as teorias enquanto relações lógicas de seu escopo ou de seus modelos semânticos. Em outras palavras, eles pensaram que as teorias poderiam ser comparadas mediante o contraste, quer dos universos de objetos, quer dos fenômenos aos quais se aplicam, ou pelo contraste de modelos determinados pelos axiomas das teorias em comparação. E, finalmente, eles adicionaram um conceito probabilístico de grau de confirmação, de acordo com o qual, em dado corpo de evidência, uma teoria é mais fundamentada do que outra se sua probabilidade indutiva for maior. Com base em ambos os conceitos lo grau de confirmação e o escopo de uma teoria), os neopositivistas elaboraram modelos indutivistas para a mudança da teoria como uma redução de uma teoria a outra. Esses modelos não permitem a eliminação de uma teoria que já obteve um alto grau de confirmação. Todas essas teorias são preservadas e ora estendidas a um domínio mais amplo, ora incluídas em teorias mais gerais. ${ }^{124} \mathrm{Em}$ todos os modelos indutivistas, o desenvolvimento do conhecimento científico pela redução é cumulativo e a redução não afeta os significados dos termos teóricos.

0 dano mais devastador à perspectiva lógica de mudança científica se deu, na década de 1970, mediante a discussão de Kuhn e Feyerabend sobre a incomensurabilidade. ${ }^{125}$ Kuhn introduziu o conceito de incomensurabilidade para enfatizar que existem teorias científicas (na verdade, tradições científicas normais), nas quais a transição entre elas não pode ser efetuada com 0 auxílio de técnicas semanticamente neutras: elas são incomensuráveis no nível sintático. Em consequência, nenhuma relação lógica entre seus enunciados pode ser estabelecida, e suas linguagens mutuamente intraduzíveis. ${ }^{126}$ Portanto, a transição entre tradições incomensuráveis não pode ser feita passo a passo, 
forçada pela experiência lógica e neutra. ${ }^{127}$ Em tais casos, conceitos antigos não apenas ganham novos conteúdos; as diferenças são mais profundas e estão para além do nível semântico. Os proponentes das teorias incomensuráveis diferem em seus padrões ou definições de ciência, e eles "praticam seus intercâmbios" em mundos diferentes. Em consequência, "os dois grupos de cientistas enxergam coisas diferentes quando olham a partir do mesmo ponto para a mesma direção". ${ }^{128}$

Feyerabend apresenta seu conceito de incomensurabilidade em oposição ao de Kuhn. ${ }^{129}$ Ele considera a incomensurabilidade conceitual das teorias concorrentes e acentua a natureza relativa da incomensurabilidade que aparece somente a partir de certos pontos de vista filosóficos. Consoante Feyerabend, duas teorias incomensuráveis "usam conceitos que não podem ser introduzidos nas relações lógicas normais de inclusão, exclusão e sobreposição". ${ }^{300}$ Isso significa que "as condições para a formação do conceito em uma teoria proíbem a formação dos conceitos básicos da outra". ${ }^{131}$ Em consequência, as teorias que, em sua interpretação habitual, vêm a ser incomensuráveis são desmembradas dedutivamente, tais como as mecânicas geral e clássica e a teoria quântica. A incomensurabilidade das teorias não exclui a possibilidade de suas comparações, embora, como diz Feyerabend, a "comparação por conteúdo, ou verossimilitude, estava, é claro, fora de questão". ${ }^{132}$ Na sua compreensão, é possível comparar teorias referindo-se aos seguintes critérios de preferências teóricas: simplicidade e coerência de uma teoria, o número de fatos previstos, e a conformidade da teoria como outras teorias básicas e com princípios metafísicos. Feyerabend destaca que a incomensurabilidade tem uma importante consequência para uma abordagem realista da cognição, uma vez que "certamente não podemos assumir que duas teorias incomensuráveis tratem de uma única e mesma situação objetiva". Por isso, "a menos que queiramos presumir que elas não tratam de coisa alguma, temos de admitir que elas lidam com mundos diferentes e que a mudança (de um mundo para o outro) foi trazida por um desvio de uma teoria para a outra". ${ }^{133}$

A discussão da incomensurabilidade teve um resultado mais geral do que aquele de revelar a inadequação da sintaxe lógica para os estudos sobre a mudança teórica. A tese da incomensurabilidade:

(...) põe em questão a versão moderna do objetivismo, o qual presume haver, ou que deve haver, um quadro epistemológico comum, neutro, através do qual podemos avaliar racionalmente teorias e paradigmas concorrentes; ou que há um conjunto de regras (que o filósofo ou o epistemólogo podem "descobrir") que nos dirá 'como o acordo racional pode ser alcançado a respeito do que resolveria a questão sobre todo ponto onde enunciados parecem conflitar.'. ${ }^{134}$

Conforme Bernstein corretamente aponta, o debate sobre a incomensurabilidade enfraquece o dogma de um quadro universal, lógico e linguístico de comparação, a existência do que é confirmado (ou requerido) pelo desenvolvimento da ciência. ${ }^{\text {ee }}$ Esse debate permitiu aos filósofos solapar o dogmatismo objetivista e reabrir o problema a respeito do que estamos fazendo quando comparamos paradigmas, teorias e jogos de linguagem. ${ }^{135}$

Embora os neopositivistas elaborassem modelos de redução teórica, foi a tradição metodológica, e não 0 empirismo lógico, que se encarregou do problema do desenvolvimento científico e ofereceu diferentes modelos epistemológicos (racionalistas) sobre a mudança científica. Exemplos paradigmáticos são a concepção de "Mundo 3" de Popper, e a metodologia dos programas de pesquisa científica de Lakatos. Tais modelos racionalistas geralmente tratam a mudança científica de modo purificado, ou seja, enquanto mudanças de conhecimento científico descontextualizado, desincorporado. Em seguida, de acordo com a tradição neopositivista, o conhecimento científico é decomposto nesses modelos em unidades, transformações que são determinadas por regras metodológicas. Finalmente, os resultados da crítica antiempirista são aceitos, e o problema da mudança científica se refere principalmente às teorias científicas. Desconsiderando as particularidades dos diferentes modelos, eles são uniformemente chamados de modelos de mudança teórica.

Os modelos de mudança teórica dividem-se em acumulativos e teleológicos. Segundo os modelos acumulativos, 0 crescimento do conhecimento científico consiste no acúmulo estável de fatos, ou de teorias com graus cada vez maiores de verossimilhança, ou aquelas que melhor solucionam nossos problemas cognitivos, ou ainda que são cada vez mais 
úteis para prever e a manipular a realidade. Em conformidade com os modelos teleológicos, o progresso consiste na aproximação cada vez maior com a verdade, quer por meio da apreciação do aprimoramento cognitivo no caminho já percorrido, quer em termos de decréscimo do distanciamento em relação às nossas metas epistêmicas planejadas. ${ }^{137}$

A concepção de Popper retrata a história da ciência como um processo objetivo do crescimento do conhecimento desencarnado. 0 crescimento procede por força de uma sucessão sem fim de estruturas de desenvolvimento, ou, antes, sequências, cada uma das quais é composta de um problema, suas soluções provisórias (hipóteses), testes falseadores e novos problemas que resultam do falseamento. ${ }^{138} 0$ método da ciência determina tanto as sequências de desenvolvimento quanto a sucessão daquelas sequências. A diferença entre os modelos popperiano e indutivista resume-se ao fato de que, na concepção dos indutivistas, o progresso consiste na acumulação da verdade, enquanto, na de Popper, quer dizer realizado mediante sucessiva eliminação de falsos enunciados da ciência. Por outro lado, a concepção de Popper compartilha com os modelos logicistas (indutivista) a profunda convicção de que a ciência é progressiva. Ademais, se enunciados verdadeiros ou falsos compõem conjuntos infinitos, o progresso da ciência, como é encarado por ambas as perspectivas, não pode alcançar a verdade final.

Os modelos indutivistas não podem levar em conta a existência de rupturas, quebras e revoluções que desfazem o processo de acumulação estável de fatos e teorias, enquanto o modelo de Popper não pode explicar a persistência das teorias falseadas. Uma solução para essas dificuldades é oferecida por modelos mais complexos de mudança científica, tais como aqueles de Kuhn ou Lakatos.

Sob o prisma de Lakatos, quando programas científicos são estabelecidos e outros de pesquisa tornam-se possíveis, a evolução da ciência procede por meio destes de pesquisa, suas mudanças intrínsecas (constituindo turnos progressivos ou degenerativos de problemas) e revoluções esporádicas, durante as quais novos programas suplantam os já existentes. ${ }^{139}$ Lakatos não concebe a história da ciência como uma sequência de programas de pesquisa, mas, sim, como uma competição sem fim, na qual programas degenerativos são, ocasionalmente, eliminados. ${ }^{140}$ Cada programa de pesquisa é uma sequência de desenvolvimento um tanto autônoma, composta de teorias e regida por regras metodológicas comuns a todos os programas de pesquisa. Há regras que permitem a avaliação das teorias pertencentes a um dado programa enquanto progressivo ou degenerativo em termos de sua habilidade para prever novos fatos. ${ }^{141}$

0 modelo lakatosiano compartilha com o esquema popperiano um modo puramente racional (normativo e metodológico) de descrever o desenvolvimento científico: em ambos, a cognição científica está sujeita à reconstrução racional, a qual revela a "história interna" da ciência, ou melhor, as razões e os princípios epistemológicos que governam a mudança científica. 0 modelo popperiano "descobre" um padrão racional de mudança teórica tendendo à verdade objetiva; o modelo de Lakatos revela a racionalidade da substituição teórica no interior dos programas de pesquisa e nas escolhas dos programas. Tais visões de racionalidade são mantidas para garantir que a ciência está seguindo em direção à verdade. ${ }^{142}$

No modelo de Kuhn, como apresentado em A estrutura das revoluções científicas, disciplinas científicas particulares "passam pelo desenvolvimento da ciência pré-paradigmática à ciência normal, da ciência revolucionária à ciência normal e assim prossegue". ${ }^{143}$ Depois de atingir a maturidade "a transição sucessiva de um paradigma para outro via revolução é o padrão usual de desenvolvimento". ${ }^{144}$ Em outras palavras, cada disciplina madura se transforma mediante estágios ou sequências cíclicas de desenvolvimento, consistindo em um período de ciência normal, em sua crise, em uma revolução e no estabelecimento de um novo paradigma. ${ }^{145} 0$ mecanismo que produz toda a sequência de desenvolvimento é duplo: racional e psicossociológico. 0 primeiro se dá em virtude dos valores de preferências teóricas, por exemplo, precisão das previsões, simplicidade, autoconsistência, plausibilidade e compatibilidade com teorias empregadas correntemente. ${ }^{146} \mathrm{~A}$ componente psicossociológica contém uma experiência de conversão (mudança gestáltica), iniciação profissional, procedimentos de estabelecimento do consenso, estratégias de persuasão, o aprendizado de uma nova linguagem, etc. A componente psicológica é a mais essencial, tanto no caso da escolha da teoria quanto nas revoluções científicas. Os atos de escolha de teoria são determinados pelas regras metodológicas e por fatores subjetivos, tais como as experiências prévias dos cientistas, seus compromissos extracientíficos e culturais, e as diferenças básicas 
em suas personalidades. ${ }^{147} 0$ coração de uma virada revolucionária é, afinal de contas, 0 deslocamento da percepção, a mudança do modo como o mundo é percebido (mas não sentido) pelos pesquisadores individuais. ${ }^{148}$

0 modelo de Kuhn rompe com a abordagem racionalista e representa uma forma naturalista, psicossociológica de explicar as mudanças na ciência. A mudança científica na ciência não é um crescimento objetivo e racional do conhecimento compelido pelo método científico. A sucessão do paradigma não visa à verdade comum a todos os paradigmas, e a causa da proliferação de certa teoria não é a sua verossimilitude, mas as decisões dos cientistas convencidos da capacidade desta de resolver o "quebra-cabeças" [puzzles]. 0 modelo de Kuhn encara o desenvolvimento da ciência como um empreendimento comunitário, no qual razões compartilhadas, valores, convenções, bem como competências e habilidades individuais desempenham um papel importante.

Todavia, há uma afinidade essencial entre esses modelos. Todos decompõem a história da ciência em unidades que sofrem transformações ou substituições, e buscam estabelecer um mecanismo de mudança universalmente aplicável a essas unidades. Portanto, particularmente em referência à perspectiva naturalista, poder-se-ia dizer que os modelos visam uma teoria da ciência capaz de "servir para explicar o fenômeno da ciência em si mesma mais ou menos no modo como teorias científicas explicam outros fenômenos naturais". ${ }^{149}$ Feyerabend aponta que as teorias "identificam o que é permanente no fluxo da história e, assim, a tornam a-histórico". ${ }^{150}$ Dito de outro modo, os modelos de Popper, Lakatos e Kuhn são modelos teóricos ou nomológicos acerca da mudança científica. ${ }^{151}$ Eles contêm vários cenários que, supostamente, se aplicam a todo caso de mudança científica. Tais modelos são projeções de um mecanismo permanente, a-histórico (metodológico), que é mantido para gerar qualquer instância de mudança teórica na ciência. Eles oferecem uma explicação universal de como a ciência evolui (cresce ou progride em direção à verdade) em decorrência de uma sequência de mudanças teóricas.

Os modelos nomológicos têm características em comum: (1) Eles decompõem a ciência em unidades (teorias, paradigmas, programas de pesquisa); organizam aquelas unidades em sequências de desenvolvimento (problemahipóteses-teste; ciência normal-crise-revolução); e concebem o desenvolvimento da ciência como uma competição entre aquelas unidades, ou como uma sucessão das mesmas. (2) Eles aceitam a suposição não historicista de que nem uma unidade, uma sequência de desenvolvimento, nem o mecanismo que rege a dinâmica interna ou a transição de uma sequência para outra se modificam durante a história (madura, adequada) da ciência. Isso é claramente um movimento de essencialização que tem um escopo analítico muito maior do que as unidades essencializadas do empirismo e do positivismo lógico. (3) Eles concebem a teorização como a componente essencial da prática científica que decide como esta evolui.

Em consequência da decomposição, o desenvolvimento da ciência torna-se uma sequência temporal de mudanças científicas. Em outros termos, a questão do mecanismo de desenvolvimento é colocada não em referência à ciência como um todo, mas relativo a estruturas mais ou menos complexas que formam a ciência. A suposição não historicista significa que a estrutura (metodológica) da mudança científica, postulada por esses modelos, é um padrão totalmente repetível, independente do tempo, a-histórico. Logo, a ciência não é acumulativa no que diz respeito à sua dinâmica; o que acontece na ciência agora, como opera, que regras ou mecanismos direcionam a atividade científica contemporânea não dependem do que aconteceu na ciência no século anterior. 0 que acontece agora e o que ocorreu no passado dependem igualmente do mecanismo de desenvolvimento. Isto é, a descoberta do mecanismo universal possibilita a explicação de toda mudança científica.

A análise crítica da concepção tácita de um mecanismo não histórico revela certas inconsistências, as quais se seguem do tratamento dado ao não histórico como um produto do histórico, e do tratamento do histórico enquanto um produto do não histórico. Embora Kuhn, Lakatos e os seguidores de ambos considerem a ciência como um fenômeno histórico, ou seja, que tem um começo histórico definido, eles, no entanto, encaram seu desenvolvimento como resultante de um mecanismo não histórico. Isso significa que ou o mecanismo de desenvolvimento da ciência é independente da existência empírica da ciência, ou que o advento da ciência estabelece um mecanismo perpétuo que dirige a evolução ulterior da ciência. De acordo com essa visão, o que muda é o conhecimento científico incorporado 
em diferentes teorias e paradigmas ou programas de pesquisa subsequentes. 0 que não muda é o mecanismo metodológico ou psicossocial considerado produtor de conhecimento científico. Modelos fragmentados de desenvolvimento científico, como aqueles publicados por Dudley Shapere, Laudan, Peter Galison, escapam às pretensões de hegemonia dos modelos nomológicos e globais. Na perspectiva fragmentada, são assumidos o encadeamento conceitual [methodological bootstrapping] e a sobreposição da periodização da história da ciência. Os métodos, relativos aos domínios, são sustentados para se desenvolverem e se aprimorarem no curso da pesquisa. ${ }^{152}$ Laudan, por exemplo, não postula que qualquer um dos níveis que ele distingue na ciência, quer dizer, o factual, o metodológico e o axiológico, seja mais privilegiado do que outro, no sentido de que permaneça estável e provoque mudanças em outros níveis. ${ }^{153}$ Com base na tradição pragmatista, ele enfatiza que teorias mudam, métodos mudam e, mais importante, que os valores cognitivos centrais da ciência também mudam. Assim, na visão de Laudan, a ciência não consagra uma constelação fixa de valores (metas) que determinam regras metodológicas, mas progride contínua e criticamente em relação a objetivos e metas sempre mutáveis. ${ }^{154}$ No entender de Laudan, a história da ciência não é, como na percepção de Kuhn, uma sequência de revoluções durante a qual todos os elementos de unidades históricas existentes (paradigmas) mudam simultaneamente. Esse é um processo fragmentado que não possui qualquer mecanismo universal de desenvolvimento, mas que procede por meio de negociações intermináveis entre os cientistas a respeito dos fatos, dos métodos e dos valores. Em consequência, o modelo reticulado apresenta uma imagem totalmente heraclítica da ciência consoante a qual todos os seus elementos podem estar em fluxo. ${ }^{155}$

Outro adepto da abordagem fragmentada, Shapere, também rejeita explicitamente a posição que ele chama de "Pressuposicionismo Global", representado, segundo ele, por Kuhn e Feyerabend. Na ótica de Shapere, esses autores aceitam estruturas unitárias que determinam e moldam a prática da ciência. Conforme seu próprio "Pressuposicionismo Local", a ciência não muda totalmente, movendo-se de um paradigma para outro, mas gradualmente; qualquer um de seus elementos está sujeito à revisão ou rejeição; e não possui uma estrutura hierárquica, de modo que todos os seus elementos, dos enunciados, passando pela linguagem, aos padrões e objetivos, são integrados e interagem. ${ }^{156}$

A justaposição entre as perspectivas nomológicas sobre a mudança científica e os modelos fragmentados revela certo dilema, que é percebido por alguns autores como uma diferença entre história e filosofia da ciência. ${ }^{157} \mathrm{Na}$ verdade, contudo, os filósofos, cuja preocupação é o desenvolvimento da ciência, também encaram isso. Eles escolhem ou uma reconstrução generalizadora, ou uma narrativa individualizada. A primeira lhes permite entender o desenvolvimento, quer pela reconstrução racional de episódios particulares, quer por suas descrições e explicações teóricas homogêneas. A segunda lhes permite compreender as mudanças particulares como únicas e incomparáveis. Aqueles que optam por essa abordagem histórica "apoiam-se em listas, estórias e apartes, razão por meio de exemplos [reason by example], analogia, livre associação e usam regras 'lógicas' quando estas se adaptam aos seus propósitos. Eles também enfatizam a pluralidade e, através desta, a dependência histórica dos padrões lógicos". 158

0 perigo da abordagem generalizadora repousa na possibilidade da fabricação da história da ciência, em vez de apresentar uma reconstrução do desenvolvimento real da ciência. Ao passo que o da [fundada na] narrativa encontrase, por sua vez, na expectativa de que seja produzida uma série de estudos de caso, no lugar de uma visão sobre 0 desenvolvimento da ciência.

\section{Para além do logicismo, do metodologismo e do globalismo}

A filosofia da ciência do século XX foi proposta, no início, como um esforço epistemológico clássico que exigia a descontextualização, a decomposição e o estabelecimento dos fundamentos últimos, de modo a justificar o conhecimento científico como algo objetivo e certo. Seu desenvolvimento, todavia, anulou gradualmente todos os componentes do programa inicial. A justificação do conhecimento científico foi abandonada como um resultado das vãs tentativas de se justificar a indução, da rejeição da crença de que a experiência perceptual oferece um fundamento para os enunciados 
observacionais; e da constatação da nossa incapacidade de atingir um determinado conhecimento. A metodologia falsificacionista, que tomou o lugar do indutivismo, não é justificacionista, ${ }_{159}{ }^{1}$ tampouco 0 são as abordagens naturalistas acerca da cognição científica.

0 fato de o programa justificacionista ter sido deixando para trás não significa que o mesmo tenha acontecido com os ideais, que ele tentou aprovar, de objetividade e racionalidade científica. Muitos filósofos adotaram uma posição segundo a qual os padrões, critérios ou valores, para os quais a argumentação apela, são eles mesmos uma questão de comprometimento, e não de raciocínio. Eles são "dogmas" que podem somente ser descritos, não justificados. William Bartley atribui esse modo de entender a racionalidade a Wittgenstein, Putnam, Quine, Rorty, e mesmo ao "primeiro" Popper. ${ }^{160}$ De fato, Popper refere-se à fé não racional na razão ou à decisão moral. ${ }^{161} \mathrm{~A}$ aceitação de compromissos não racionais parece o único modo de evitar o dilema: ou paralisia cognitiva (causada pelo regresso infinito da justificação), ou a ameaça do círculo vicioso.

É claro que existem filósofos convencidos de que a filosofia da ciência sem dogmas não racionais seja possível; por exemplo, os popperianos acreditam que a concepção tardia de Popper a respeito da crítica racional ilimitada e autorreflexiva se sobrepõe a qualquer necessidade de um compromisso não racional. ${ }^{162}$ Entretanto, eles não atentam para o fato de que, segundo Popper, a noção de verdade objetiva ou absoluta desempenha um importante papel enquanto princípio regulativo. ${ }^{163}$ É exatamente esse princípio regulativo que é excluído do domínio do criticismo vigoroso. Proclamar que a noção de verdade absoluta seja um princípio regulativo na filosofia da ciência, como, em nossa opinião, Popper realmente faz, é adotar a fé na razão. É esse princípio que permite a Popper atribuir universalidade e insensibilidade histórica ao método científico, postulado por ele independentemente do que mostram os estudos empíricos sobre regras metodológicas seguidos pelos cientistas. Somente esse princípio permite a Popper articular suas metodologia e teoria do desenvolvimento científico. ${ }^{164}$ Além do que, esse é um compromisso puramente dogmático, um princípio estipulado que não é argumentado racionalmente, nem testado empiricamente.

Para os filósofos racionalistas, no entanto, essa inevitável solução para o dilema - ou a justificação interminável, ou o círculo vicioso - é a pior possível. Se é preciso admitir que os valores são objetos de opção não racional, isso significa um claro sinal de que seu programa racionalista é um fracasso. A razão de a filosofia da ciência racionalista ter alcançado essa posição tão miserável é o fato de que continua a sustentar a dicotomia fato-valor, algo para o qual é preciso ter bons motivos. Ao aceitar a oposição entre fatos e valores, ou razões e causas, ${ }^{165}$ não se pode deduzir juízos de valor a partir de enunciados factuais. Não se pode inferir das descrições dos cientistas, os quais seguem regras para produzir, avaliar ou substituir teorias, que, por exemplo, a verdade seja a meta suprema (mesmo que inatingível) da ciência, ou que a acumulação de conhecimento seja necessária, ou que a ciência seja capaz de transcender situações locais e produzir conhecimento cada vez mais próximo da verdade [truthlike]. Igualmente inaceitáveis são as transições dos juízos de valor para teses descritivas, por exemplo, das teses da verossimilitude às teses do realismo. Essa dificuldade não pode, é claro, ser resolvida por meio da rejeição da dicotomia fato-valor. A rejeição desta significa tratar os valores como fatos. Desse modo, a separação entre valores e fatos, e a necessidade de valores epistêmicos que não sejam puramente factuais, leva os partidários do modelo racionalista da ciência a um dilema: ou a descrição factual (por exemplo, psicossocial) de valores subjetivos, ou a descoberta (reconstrução) filosófica do que seja objetivamente racional. É por isso que perspectivas racionalistas exigem princípios regulativos que sejam compromissos e não hipóteses factuais ou teses abertas à discussão.

0 reconhecimento de que a separação entre valores e fatos é um fato histórico e cultural ${ }^{166}$ autoriza a anulação da dicotomia, embora não da diferença que a caracteriza, e abre o caminho para outra postura filosófica. Ambos os dilemas, justificação interminável ou um círculo vicioso, descrição ou valoração, podem ser declarados como artificiais. Primeiro, nenhuma descrição não factual está isenta de valores: estes entram no próprio processo de descrição e são, algumas vezes, constitutivos do que é descrito. ${ }^{167}$ Os valores, por outro lado, não são estabelecidos independentemente dos fatos: as mais abstratas estipulações axiológicas estão relacionadas a certas imagens do mundo, da ação humana, da história, etc. Em segundo lugar, a interdependência entre descrever e avaliar é simplesmente uma indicação do fato de que nossas atitudes para com o mundo (incluindo o cognitivo) envolvem valores. Isso, por sua vez, significa mais 
do que eles serem certos tipos de fatos, ou melhor, propriedades objetivas desejadas, ou metas (estados mentais). Valores epistêmicos pertencem à dimensão social da ciência, ${ }^{168}$ e funcionam nesta de um modo diferente dos objetos ou estados psicológicos. Os valores, valores epistêmicos e as normas dentre eles, não determinam nossos padrões de conduta, mas sim os regula. Ademais, o status das normas epistêmicas está mais próximo do status das regras morais do que qualquer outro tipo de regulação. Como argumenta Leszek Kolakowski, a violação de uma regra técnica produz meramente a expectativa do insucesso; a violação de um costume social resulta no sentimento de incorreção; a infração de uma lei leva ao medo da punição; e somente a transgressão de normas morais ou de tabus produz o fenômeno da culpa. ${ }^{169} \mathrm{~A}$ experiência da culpa é um ato existencial, "um ato de questionar sua própria condição na ordem cósmica, ou, em outras palavras, um sentimento de temor diante de sua própria ação que perturbou a harmonia do mundo". ${ }^{170}$ Isso pertence ao reino do Sagrado, no qual o conhecimento, o sentimento de participação na realidade última e o compromisso moral são unidos em único ato religioso. ${ }^{171}$ Não queremos afirmar que não haja diferença entre a experiência moral ou religiosa da culpa, depois de falhar na observância de uma norma, e a experiência de um cientista que viola uma regra metodológica. Sua comparação requer maiores considerações. Não obstante, como tentaremos mostrar a partir de Polanyi, há uma similaridade entre a discussão de Kolakowski sobre a convergência do entendimento e da crença [believing] no ato da participação religiosa ou mítica, e a unidade do conhecimento, do empenho para criá-lo, e a comunhão com a natureza nos atos dos participantes na ciência.

Assim, não há oposição entre a narrativa sociológica ou histórica, e, logo, factual, da ciência, e sua interpretação ou avaliação filosófica a partir da perspectiva dos valores, dos padrões e regras epistêmicos. 0 que distingue 0 entendimento filosófico da ciência dos entendimentos sociológico e histórico é a busca do diálogo no interior das tradições filosóficas, abordando seus problemas e usando conceitos que foram elaborados por aquelas tradições, etc. Se não há um hiato genuíno, contudo, essas perspectivas não precisam permanecer separadas e podem ser combinadas em uma visão coerente.

Como já acentuamos na Introdução, optamos por uma maneira de combiná-los que pode levar ao "entendimento contextual". ${ }^{172}$ Esta é uma compreensão filosófica da ciência enquanto um elemento essencial da forma de vida em que habita o filósofo. Esse fato existencial inevitável, participando de certo modo, presente aqui e agora, a forma de vida, é uma fonte de aspecto situacional indispensável de qualquer descrição e avaliação científica ou filosófica. É sempre vitalmente a descrição e avaliação de alguém, e, portanto, pertencem ao contexto cultural da pessoa. A respeito disso não podemos transcender a nossa localidade. Todavia, isso significa que, reconhecida a nossa localidade, não podemos procurar conceitos que nos permitiriam entender tanto a nós mesmo quanto outras pessoas vivendo em suas localidades? Em outras palavras, é possível invocar conceitos como "objetividade" e "racionalidade" e usá-los no entendimento contextual da ciência enquanto sabemos que não são culturalmente neutros? Nossa resposta é, naturalmente, negativa. 0 fato de não serem culturalmente neutros não é razão contra o emprego daqueles conceitos. 0 reconhecimento de que somos seres situados não proíbe a aplicação de nossos conceitos em outros contextos culturais.

Por conseguinte, não rejeitamos a possibilidade de valorar [valuating] a racionalidade da ciência. Afinal de contas, a deliberação e os atos racionais que visam valores epistêmicos caracterizam a atividade dos cientistas. Acreditamos, entretanto, que identificar a racionalidade com um conjunto de regras e padrões metodológicos a-históricos (com 0 Método da ciência) subjuga e essencializa a história da ciência. Por outro lado, pressupor que a racionalidade científica seja histórica no sentido de que o desenvolvimento da ciência é um doloroso desdobramento de uma racionalidade científica predestinada, é seguir a perspectiva hegeliana com a sua metafísica duvidosa. De mais a mais, a aceitação de qualquer uma dessas visões significa adotar a ilusão de que a ciência é produzida por um sujeito cognitivo pura e totalmente determinado, isto é, um ser idealizado cuja atividade é reduzida a atos cognitivos e conduzido por regras objetivas. Essa abordagem bloqueia qualquer recurso à concepção de ciência enquanto atividade de cientistas e comunidades científicas reais. No entanto, esta é uma perspectiva da ciência ainda corrente em nossos dias. Assim, parece óbvio que "devemos estar preparados para procurar todas as explicações abstratas sobre a mudança científica em outro nível, onde as questões têm a ver com a pessoa, cujas concepções, teorias e ideais explanatórios estão em debate". ${ }^{173}$ A realização dessa tarefa exige que ultrapassemos os limites da maioria das filosofias contemporâneas da 
ciência em três pontos: a concepção do pesquisador, o entendimento da natureza social da ciência e a compreensão de sua historicidade.

Os filósofos da ciência parecem crer que a racionalidade e a objetividade da ciência podem ser preservadas à custa de uma radical purificação epistemológica do conceito do cientista. Assim, o conhecimento científico é purificado "das distorções produzidas pelos laços [allegiances] sociais e pessoais dos cientistas". ${ }^{174}$ Tais purificações variam entre considerações dos cientistas enquanto sujeitos que almejam objetivos puramente cognitivos, por meio da visão de que são participantes de uma história "interna", ou seja, seres que fazem escolhas de um modo completamente racional (honestidade intelectual), ${ }^{175}$ à crítica cognitiva de Popper, para quem os cientistas estão totalmente sujeitos ao método da ciência. Como resultado de tais idealizações, o cientista é "um conhecedor demente que funciona de forma específica". ${ }^{176}$

É óbvia a inadequação de tal visão epistemologicamente idealizada, purificada e a-histórica do cientista. É verdade que ela falha em proteger o ideal de objetividade científica; porém, isso é menos óbvio. 0 ataque mais violento a essa perspectiva foi empreendido por Michael Polanyi. 0 ideal de conhecimento objetivo e despersonalizado, livre de paixões e testado de acordo com as regras codificadas do método científico não é somente falso enquanto descrição, mas irrealizável enquanto projeto normativo. Ademais, quer dizer uma ameaça à ciência. ${ }^{177}$ Se os filósofos declaram que o conhecimento não é totalmente determinado (pela experiência ou pelos algoritmos metodológicos), eles devem adotar um conceito de cientista como "uma pessoa com o direito de moldar seu conhecimento baseado em seu próprio julgamento, sem maiores especificidades". ${ }^{178}$ Ou melhor, se o conhecimento científico não é produzido pelo Método da ciência, mas por cientistas, a filosofia da ciência deve usar um conceito do sujeito conhecedor que proporcione entendimento sobre como o conhecimento científico (sejam quais forem os seus atributos) é produzido. Se nossas crenças são meramente hipóteses, cujo valor não é garantido pela lógica nem pelo método, precisamos de um conceito do conhecedor que não arruíne a noção de responsabilidade pessoal por nossas crenças. ${ }^{179}$

A concepção de "cientista" de Polanyi é profundamente existencialista e psicológica, moldada por suas leituras de Martin Heidegger e da psicologia da Gestalt. Tal concepção apoia seu ideal de conhecimento científico como um fundamento racional e objetivamente verdadeiro da sociedade livre. 0 cientista é uma pessoa "responsável pela condução e pelas credenciais das descobertas científicas". ${ }^{180}$ As categorias centrais de Polanyi são os conceitos de pessoa [person] e de pessoal [personal], mas estes não se referem ao lado subjetivo da oposição subjetivo/objetivo. 0 pessoal transcende essa dicotomia e nos permite perceber como 0 objetivo e o subjetivo estão articulados; o pessoal vem a ser no curso de uma ação (cognitiva) responsável baseada no compromisso e "guiada por paixões individuais". ${ }^{181}$ Há relação dialética estreita entre o pessoal, o objetivo e o universal: "0 pessoal vem à existência por meio da afirmação da intenção universal, e o universal é constituído ao ser aceito enquanto o termo impessoal desse compromisso pessoal". ${ }^{182} \mathrm{~A}$ validade intersubjetiva universal do conhecimento não é garantida pelos dados empíricos disponíveis a qualquer observador qualificado, nem por regras de criticismo racional. Universalidade, enquanto um valor elaborado, não existe sem atos pessoais de reconhecimento [recognition], sendo reconhecida [acknowledged] como um objetivo, e a aceitação da responsabilidade por sua realização. Por outro lado, mediante ato de comprometimento, a universalidade (objetividade) transforma um ato subjetivo em um ato pessoal, ou seja, um ato guiado por paixões e imerso em significados [meanings] e valores. ${ }^{183}$ Por consequência, um ato de compreensão (científica), que é um ato pessoal, "não é um ato arbitrário nem uma experiência passiva, mas um ato responsável que alega validade universal" . ${ }^{184}$

Há também uma relação dialética entre liberdade pessoal e a conformidade às regras. Este é o paradoxo da dedicação: "uma pessoa afirma sua independência racional mediante a obediência aos ditames de sua própria consciência, isto é, das obrigações estabelecidas para si mesmo por si mesmo... Qualquer devoção envolve um ato de autocoação [self compulsion]". 185

Na visão de Polanyi, a objetividade, a razoabilidade e a validade universal não são atribuídas ao conhecimento científico a priori simplesmente por ser científico; nem são justificadas pelas regras metodológicas. Elas revelam a si mesmas como aspectos indispensáveis à atividade cognitiva pessoal: eles constituem e condicionam simultaneamente os atos pessoais: 
Atribuímos aos nossos padrões a característica de serem absolutos, porque, ao empregá-los como partes de nós, confiamos neles enquanto refúgio derradeiro, mesmo quando se reconhece que não são realmente partes de nós mesmos, nem feitas por nós mesmos, mas extrínsecas a nós. No entanto, essa confiança pode se dar apenas em circunstâncias passageiras, em algum lugar e tempo particulares, e aos nossos padrões será concedida a característica de serem absolutos dentro desse contexto histórico. ${ }^{186}$

A maneira como Polanyi aborda as regras, os padrões e os valores nos permite entender nossas interdependências dialéticas, nossas ações e suas consequências, e nossos valores sem apelar para qualquer autoridade axiológica externa. No interior dessa teia de dependências, as regras e os valores são constituídos e objetivados por nossos atos de obediência a ambos; nossas ações puramente factuais, descritas seja em termos físicos, neurofisiológicos ou psicológicos, ganham sentido e podem ser avaliadas; e seus resultados, como o conhecimento científico, tornam-se a incorporação de regras e padrões superficialmente objetivos e coercivos.

A análise de Polanyi também é útil para se identificar as consequências negativas do anti-holismo ainda remanescente na filosofia da ciência. Os individualistas ou, de forma mais abrangente, os anti-holistas acreditam que extrair as partes de um todo não despoja as partes de suas características essenciais. Entretanto, se é verdade que conseguimos controlar as partes do todo, em termos de sua contribuição ao funcionamento desse todo, então os anti-holistas desconsideram o fato de que a transposição de um todo significativo em seus elementos constitutivos irá privá-los de propósito e sentido. ${ }^{187}$ Está claro que eles [os anti-holistas] acabam ficando com uma imagem inadequada.

A abordagem holística de Polanyi leva-o a reconhecer a conexão dialética entre descoberta científica e a ciência como um todo:

Toda descoberta científica é conservadora, no sentido de que preserva e expande a ciência como um todo, e, nessa medida, confirma a visão científica do mundo e fortalece sua manutenção em nossas mentes; porém, nenhuma grande descoberta pode falhar também em modificar o ponto de vista da ciência, e algumas mudaram isto profundamente. ${ }^{188}$

O holismo permite a Polanyi clarificar por que não podemos tratar a ciência de um modo objetivo, livre da ideia de compromisso. Não podemos estabelecer uma concepção objetivista da ciência porque esta, enquanto uma tradição e um sistema organizado de autoridade, não existe sem comprometimento. É a atividade responsável dos cientistas que preserva a ciência como tradição, e é a obediência deles à tradição que confirma a ciência como uma autoridade. ${ }^{189}$ Por outro lado, para Polanyi, o conceito de cientista é impossível sem relacionar o cientista à tradição e à autoridade científica. Contudo, a concepção de Polanyi tem uma inclinação individualista; ele se concentra em uma compreensão existencialista da prática científica tal como observada do ponto de vista do cientista. Logo, em virtude disso, o caráter social permanece em segundo plano. Ademais, em certo sentido, segundo a concepção de Polanyi, a natureza histórica da ciência também permanece em segundo plano. Não existe cientista historicamente universal. As pessoas que trabalham na ciência em épocas diferentes e em países diferentes desempenham, na verdade, papéis muito diferentes. Consideraremos esse problema na última parte do artigo.

Como já enfatizamos, a natureza social da ciência foi introduzida na filosofia da ciência pós-empirista pelos globalistas, e muitos autores concordariam, atualmente, com o que Toulmin disse: "As ciências naturais desenvolvidas historicamente são questões essencialmente comunais, ultrapassam uma única geração humana e não podem ser caracterizadas em termos de pensamentos e procedimentos de indivíduos isolados". ${ }^{190}$ Kuhn, um dos mais vigorosos advogados da filosofia da ciência socializada, está convicto de que o solipsismo metodológico, segundo o qual a ciência é, em princípio, o jogo de uma pessoa só, provará ter sido um erro prejudicial. ${ }^{191}$ Se não há algoritmo para escolher uma teoria que se aplique do mesmo modo a todo cientista singular, então a ciência não é um jogo de uma pessoa só (tampouco um jogo sem um jogador). É a comunidade de especialistas, acredita Kuhn, que toma a decisão efetiva, e não os membros individuais. ${ }^{192}$ 
A consciência da necessidade de se prestar mais atenção ao aspecto social da ciência não significa que sua imagem na filosofia da ciência contemporânea não seja simplificada. A primeira resume-se a conceber grupos e comunidades científicas como supraindividuais, e a atribuir-lhes características humanas individuais (uma mente, um interesse, características compartilhadas pela maioria dos membros de um grupo, etc.). Kunh, por exemplo, admite que esse foi "um nocivo erro de categoria" cometido por ele: "0 mais notório exemplo desse erro na Estrutura é o meu repetido discurso sobre as mudanças gestálticas enquanto características da experiência sofrida pelo grupo. "... [um grupo] não faz escolhas nem toma decisões". ${ }^{193}$ Kuhn admite também que "é cada vez mais reconhecido que um grupo não é apenas a soma de suas partes e que a identidade de um indivíduo, em parte, consiste (não simplesmente, mas também é determinado pelos) nos grupos dos quais ele/ela é um membro", e conclui: "Precisamos muito aprender modos de entender e descrever os grupos que não se enquadram nos conceitos e termos que aplicamos sem problemas aos indivíduos". ${ }^{194}$ Kuhn não é sociólogo;195 ele crê que para se entender a natureza comunal da ciência, e para evitar tratar grupos como indivíduos, a filosofia deveria compreender "a maneira como um conjunto particular de valores compartilhados interage com as experiências particulares compartilhadas por uma comunidade de especialistas, a fim de garantir que a maioria dos membros do grupo irá, enfim, encontrar um conjunto de argumentos mais decisivo do que outros". ${ }^{196}$ Nessa empreitada, a filosofia deveria se voltar para a biologia evolutiva. ${ }^{197}$

Essa ideia não é, contudo, muito promissora. Acreditamos que a consideração da ciência em termos análogos aos dos conceitos biológicos de "reservatório genético" [gene pool] e mecanismos de seleção e mutação não ofereça "pistas importantes para mostrar em que sentido a ciência é intrinsecamente uma atividade comunitária". ${ }^{198}$ Salientemos, novamente, que Kuhn espera que a biologia evolutiva possa ser uma fonte de inspiração para compreender a natureza social da ciência, e não a sua história. Todas as teorias da evolução contêm conceitos referentes a unidades (organismos, genes, etc.) sobre as quais a mutação e outros mecanismos de seleção trabalham, em conjunto com o conceito de ambiente. Portanto, eles podem ser úteis àqueles filósofos da ciência que querem dizer que o ambiente (social) da ciência funciona como uma restrição sobre a operação da seleção. Isso não é, todavia, o que Kuhn tem em mente. Ele quer usar as teorias da evolução para esclarecer a natureza social da ciência em si mesma. Entretanto, isto não parece possível sem o recurso, pelo menos, a conceitos referentes às relações entre indivíduos. Nas teorias da evolução, não há conceitos que se refiram às relações entre unidades nas quais a mutação e a seleção operam; mesmo o conceito de população de organismos é reduzido de forma padronizada ao conceito de "reservatório genético".

Além disso, utilizar os recursos explicativos da biologia evolutiva não pode ajudar a superar outra fonte mais fundamental da inaptidão dos filósofos para alcançar a natureza social da ciência. Tipicamente, o social é concebido como um mero contexto no qual avança a cognição, ainda entendida em termos individuais. A realização da ciência é situada simplesmente dentro de sítios culturais, mas continua a empregar os conceitos epistemológicos tradicionais de cognição enquanto uma atividade individual. ${ }^{199}$ Citando Kuhn novamente: quando ele descreve a prática que constitui a ciência normal como "uma tentativa vigorosa e devotada de forçar a natureza a entrar nas caixas conceituais fornecidas pela educação profissional", ou como "uma tentativa de forçar a natureza a entrar na caixa pré-formada e relativamente inflexível que o paradigma oferece", ${ }^{200}$ ele aceita um conceito tradicional de cognição e de pesquisa científica. A cognição científica é: uma relação entre o cientista e a natureza, e a atividade individual de solucionar quebra-cabeças. ${ }^{201}$

Esse é um ponto crucial para qualquer epistemologia socializada ou cultural. Esta não pode ser bem-sucedida sem mostrar que a cognição em si mesma é um empreendimento social. Argumentar que a cognição tem lugar em um contexto social, ou que é influenciada ou determinada por fatores sociais externos, não é suficiente. Assim considerada, a cognição permanece uma atividade individual, um jogo entre sujeito e objeto ou entre a mente humana e a Razão objetiva, embora esteja localizada em um contexto social. Por esse motivo, o conceito de "social" é sempre secundário e simplesmente insignificante, porque o social não pertence ao cognitivo.

Aliás, entender a natureza social da ciência é crucial para compreensão de sua natureza histórica. A ciência pode ser vista como o processo de selecionar hipóteses, soluções, explicações apropriadas, etc. regidas por regras (transcendentais) de racionalidade. No entanto, esses itens devem, em primeiro lugar, ser construídos (pode ser 
encarada como uma questão psicológica) e, então, objetivados. Em termos popperianos, eles devem se tornar um elemento do "Mundo 3" ou, como diz Lakatos, devem se tornar propriedades públicas. Não podem, porém, tornarem-se propriedades públicas sem os processos, as instituições, as relações sociais, etc., que constituem a esfera pública. Parece que mesmo historiografias da ciência tão antissociais quanto as de Popper e Lakatos não podem seguir (em detalhe) sem referências aos fenômenos sociais relevantes. Acreditamos, por isso, que o caráter social da ciência e a natureza social da cognição não podem ser compreendidos sem a aceitação de que "o conhecimento científico não é construído por indivíduos aplicando um método, mas por indivíduos interagindo com outros de maneira que modificam suas observações, teorias, hipóteses e padrões de raciocínio". gt Em outras palavras, o conhecimento científico é "o resultado de um diálogo crítico no qual indivíduos e grupos que conservam pontos de vista diferentes interagem mutuamente". ${ }^{203}$

Embora o deslocamento da descrição sincrônica da ciência para as representações diacrônicas realizadas na filosofia da ciência contemporânea pareça irreversível, muitos defensores da imagem histórica da ciência possuem um entendimento simplista do que seja o "histórico". Eles veem a história como um passado objetivo fornecendo um conjunto de episódios individuais que podem ilustrar seus modelos de desenvolvimento. ${ }^{204}$ Quer dizer, a história se torna objetivada e é considerada como se existisse independentemente de como a interpretamos. Esquadrinhar a história em busca de exemplos é uma atitude baseada em um atomismo implícito, que afirma não haver qualquer outra coisa no desenvolvimento histórico do que a repetição e a agregação de eventos. ${ }^{205}$ Ademais, episódios históricos, no papel de exemplificações de mudanças teóricas, são extraídos de seus contextos históricos e tratados como se "falassem por si mesmos". Ambas as suposições - a saber: que a história é um passado objetivo, e que os episódios históricos são átomos independentes de história - são ontológica e epistemicamente ingênuas.

0 passado da ciência não é simplesmente uma seqüência temporal objetiva de eventos separados da ciência contemporânea. 0 passado da ciência deve ser observado em sua conexão dialética com a ciência moderna e com os filósofos e historiadores da ciência contemporâneos. Não pertencemos ao passado da ciência; nossa contemplação sobre isso se dá dentro do horizonte do presente. Mas vemos nisso o passado da ciência que é a nossa atual. Há, assim, continuidade e conexão internas entre o passado e o presente da ciência. Isso, porém, não pode ser compreendido pelos modelos nomológicos de mudança de teoria, precisamente porque estes devem desconsiderar a continuidade da ciência, de modo a dividi-la em episódios exemplares ou épocas. A continuidade requer entendimento hermenêutico, em vez de uma formulação de generalizações abstratas que pertencem a padrões históricos percebidos. 0 que precisa ser entendido é o papel da tradição que demanda interpretação hermenêutica. 0 passado é contínuo e ativamente apropriado, enquanto tradição, nos correntes padrões de pensamento e de modos de ser. A interdependência dialética interna entre tradição e pensamentos atuais requer análise detalhada. Para esse fim, empregamos criticamente a hermenêutica gadameriana.

A moral que queremos extrair desses comentários vai de encontro à tendência objetivadora da filosofia da ciência. A continuidade interna da ciência passada e contemporânea não precisa ser reduzida à operação de um mecanismo transformador que mobiliza, de forma constante, unidades estruturalmente idênticas de conhecimento científico. $\mathrm{Ou}$ melhor, continuidade não é uniformidade [sameness] e não precisa ser atribuída à ciência com o auxílio de um modelo universal de mudança teórica ou de substituição de paradigma. Épocas diferentes, que constituem a história da ciência, podem ser chamadas de "científicas", se uma época puder mostrar que leva a uma época subsequente, e, finalmente, à ciência contemporânea; e se puder demonstrar que resulta de suas predecessoras, de modo que está ligada, por intermédio delas, ao início da ciência. Em outros termos, a continuidade pode ser explicada como uma propriedade da ciência que é criada durante a atividade histórica dos cientistas. Essa prática histórica da ciência possui seu próprio dinamismo, que pode ser entendido como uma manifestação particular do dinamismo que governa a cognição humana. Seu núcleo é a capacidade para autotranscender, algo que, na ciência, é compelido pela experiência e pelo seu envolvimento na prática social e tecnológica.

Essas afirmações acerca da natureza social e histórica da ciência requerem - certamente - análises mais profundas. Tratá-las da maneira que merecem, contudo, ultrapassariam os limites da presente discussão. ${ }^{206}$ 


\section{Notas e referências bibliográficas}

James E. McGUIRE é professor de História e Filosofia da Ciência da Universidade de Pittsburgh, EUA. E-mail: jemcg@pitt.edu.

Barbara Tuchanska é professora do Departamento de Filosofia da Universidade de Lodz, Polônia. E-mail: barbtu@filozof.uni.lodz.pl.

1 Cf. WARTOFSKY, M. The Relation between Philosophy of Science and History of Science. In: WARTOFSKY, M. Models. Dordrecht: Reidel, 1979. p. 125-6; TOULMIN, S. E. From logical analysis to conceptual History. In: ACHINSTEIN, P., BARKER S. F. (Ed.). The Legacy of Logical Positivism. Studies in the Philosophy of Science. Baltimore: The Johns Hopkins University, 1969. p. 48-50; FEYERABEND, P. K. Farewell to Reason. London: Verso, 1987. p. 118-9, $294-5$.

2 McGUIRE, J. E. Scientific Change: Perspectives and proposals. In: SALMON, M. H. et al. Introduction to the Philosophy of Science: A Text by Members of the Department of the History and Philosophy of Science of the University of Pittsburgh. Englewood Cliffs, N.J.: Prentice Hall, 1992. p. 134.

$3 \quad$ Ibid., p. 144.

4 ibid., p. 134.

5 BERNSTEIN, R. J. Beyond Objectivism and Relativism: Science, Hermeneutics and Praxis. Philadelphia: University of Pennsylvania Press, 1983. p. 24.

6 De acordo com um dos empregos do termo "naturalista" (naturalistic), na filosofia da ciência anglo-americana, o usamos em oposição a "normativista" (normativistic) e subsumimos a isso as abordagens biologistas, psicologistas e sociologistas (cf. CALLEBAUT, W. (Ed.) Taking the Naturalistic Turn or How Real Philosophy of Science is done. Chicago: The University of Chicago Press, 1993. p. 11-45).

7 BERNSTEIN, Op. cit, p. 75

$8 \quad$ lbid.

9 BERNSTEIN.

10 Ver McGUIRE, 1992, p. 145-6, onde o termo é introduzido pela primeira vez. Basicamente, uma perspectiva globalista se interessa, em primeiro lugar, pelo desenvolvimento da ciência.

11 Aqui, o que temos em mente são visões como aquela oferecida por Frederic Suppe (SUPPE, F. The Search for Philosophic Understanding of Scientific Theories. In: SUPPE, F. (Ed.). The Structure of Scientific Theories. Chicago: University of Illinois Press, 1977). De fato, nós dois propusemos tais visões sinópticas (cf. McGUIRE 1992; TUCHANSKA, B. The Methodological Problem of the Development of Science versus the Historical Problem of How Science Performs Its Social Functions. In: The Polish Sociological Bulletin, 1980/3: p. 5-24, 1980.

12 Cf. McGUIRE, 1992; p. 148. SUPPE, 1977, p. 7; TOULMIN, S., 1969, p. 34-5.

13 CARNAP, R. Intellectual Autobiography. Part III. In: SCHILPP, P. A. (Org.). The Philosophy of Rudolf Carnap. La Salle, Illinois: Open Court, 1963. p. 50.

14 CARNAP, R. The Logical Syntax of Language, London: Routledge and Kegan Paul, 1937. p. 279.

15 CARNAP., 1937, p. 282; 1963, p. 53.

16 Essa purificação lógica do conhecimento científico foi rejeitada por uma abordagem semântica das teorias científicas elaborada por Evert Beth, Suppe, Joseph Sneed, Wolfgang Stegmüller, e outros, assim como o modelo de acesso elaborado por Mary Hesse. A abordagem semântica torna a linguagem irrelevante para as teorias científicas e, em vez de estudar a formulação linguística das teorias, concentra-se nas teorias entendidas como famílias de modelos projetados.

17 SUPPE, Op. cit, p. 60.

18 Afirmar que a análise dos empiristas lógicos é "essencialista" justifica-se pelo fato de que, para Carnap e outros empiristas lógicos, suas analises da linguagem (científica) são uma reconstrução lógica e não um estudo sociolinguístico da descoberta de regras empíricas da lógica e da sintaxe, que as pessoas seguem em atos de comunicação linguística (CARNAP, 1937, p. 5). Mesmo os empiristas lógicos não poderiam, contudo, ignorar a natureza social e histórica da linguagem. Há um nítido elemento empirista no tratamento de Carnap sobre a linguagem em Testabilidade e Sentido.

19 CARNAP, Op. cit, 1963, p. 57.

20 Ibid.; RUSSELL, B. My Philosophical Development. New York: Simon and Schuster, 1959. p. 48 e 58. CARNAP, Op. cit, 1963, p. 57.

21 McGUIRE, Op. cit, p. 144.

22 Um exemplo de sua artificialidade é o fato de que, junto a outras doutrinas da tradição neopositivista, por exemplo, a teoria verificacionista do sentido, [verifiability theory of meaning], gerou o problema do estatuto ontológico das entidades teóricas. A maneira como esse problema foi estabelecido pode significar que este era, pelo menos em certa medida, um pseudoproblema, isto é, uma questão gerada pelo próprio modo como a tradição analítica entendeu a experiência, o sentido e a aceitabilidade do conhecimento científico. Conforme indica Dudley Shapere, as dificuldades com a aceitação de enunciados sobre a existência de objetos teóricos, que não podem ser diretamente verificados, por exemplo, os elétrons, não resultam de "alguma opacidade intrínseca do conceito de existência". Elas são geradas pela rigidez da distinção teórico/observacional e pela estreiteza do modo de se entender 0 sentido e a aceitabilidade (SHAPERE, D. Notes toward a Post-Positivistic Interpretation of Science. In: ACHINSTEIN, P., BARKER, S. F. (Ed.). The Legacy of Logical Positivism. Studies in the Philosophy of Science. Baltimore: The Johns Hopkins Press, 1969. p. 128-9). Se a existência de um objeto só pode ser determinada empiricamente e se o sentido do conhecimento teórico deve apoiar-se sobre a experiência (direta), não há, então, como se estabelecer a existência de entidades teóricas.

23 QUINE, W. V. O. From the Logical Point of View. Cambridge, Mass.: Harvard University Press, 1953. p. 42.

24 POLANYI, M. Personal Knowledge: Towards a Post-Critical Philosophy. New York: Harper \& Row, 1964. p. XIII, 49-65.

25 BUCHWALD, J. Z. Design for Experimenting. In: HORWICH, P. (Ed.). World Changes: Thomas Kuhn and the Nature of Science. Cambridge, Mass: The MIT Press, 1993. p. 180-1.

26 No caso de certos autores, essa abordagem pragmática da ciência era, de fato, uma visão pragmatista, derivada de ideias do pragmatismo.

27 TOULMIN, S. E. Human Understanding, v. 1: General Introduction and Part I, Princeton, N.J.: Princeton University Press, 1972. p. 84. 
Ibid., p. 486 .

29 BARNES, B. Scientific Knowledge and Sociological Theory. London: Routledge \& Kegan Paul, 1974. p. 45.

30 POPPER, K. R. The Logic of Scientific Discovery, London: Hutchinson of London. 1959, p. 52.

31 Ibid., p. 27, 32, 59 .

32 Ibid., p. 53-4.

33 LAKATOS, I. Philosophical Papers. vol. 1, Cambridge: Cambridge University Press, 1978, p. 102, p. 110.

34 Cf. BARNES, Op. cit, p. 32, 45.

35 WATKINS, J. W. N. The Unity of Popper's Thought. In: SCHILPP, P. A. (Ed.) The Philosophy of Karl Popper, v. 1. La Salle, Illinois: Open Court, 1974. p. 400 (grifos nossos).

$36 \quad$ LAKATOS, Op. cit, p. 113-4.

37 POPPER, K. R. Objective Knowledge: An Evolutionary Approach. Oxford: The Clarendon Press, 1972. p. 47.

$38 \quad$ Ibid., p. 59

40 BERNSTEIN, Op. cit, p. 23.

41 CURTIS, R. Institutional Individualism and the Emergence of Scientific Rationality. Studies in History and Philosophy of Science 20. 1989. p. 94.

42 Ibid.

43 FEYERABEND, P. K. Against Method: Outline of an Anarchistic Theory of Knowledge (ed. rev.). London: Verso [1975], 1988, p. 160-4; LAKATOS, Op. cit, 1978, p. 123-8. Seus passos seguintes são, todavia, bem diferentes. Feyerabend se recusa, com razão, a aceitar que a filosofia da ciência possa impor restrições sobre os métodos e procedimentos da ciência, e resume sua crítica na sentença meta-metodológica "tudo vale" (FEYERABEND, Op. cit, 1988, p. 248-9; LAKATOS, Op. cit, 1978, p. 39-40; BERNSTEIN, Op. cit, 1983, p. 62-3). Por sua vez, Lakatos responde mediante a declaração de que sua metodologia é aquela em que programas de pesquisa concorrentes são avaliados comparativamente. Cada um é potencialmente falseável e potencialmente capaz de degenerar. A estratégia para sua avaliação é escolher a melhor, à luz de sua habilidade para racionalizar eventos históricos reconstruídos, consoante a seguinte fórmula: "(1) faz-se uma reconstrução racional; (2) tenta-se comparar essa reconstrução racional com a história real e criticar tanto a reconstrução racional por falta de historicidade, quanto a história real por falta de racionalidade" (1978, 52-3). Não está claro como tal imagem racionalizada pode ser comparada com a história real e acusada de falta de historicidade, uma vez que não é uma descrição empiricamente orientada de um dado episódio. É uma reconstrução normativa que prescreve como a ciência deve proceder de modo a permitir-nos criticar a realidade por falta de racionalidade. A afirmação de Lakatos de que estudos de caso teoricamente racionalizados podem ser suplementados pela ajuda da história "externa" da ciência é igualmente dúbia. Pode-se ter a impressão de que o objetivo das reconstruçães racionais é simplesmente tornar a própria metodologia de Lakatos imune à falsificação.

44 Foi demonstrado por David Miller e Pavel Tichy que, dadas duas teorias falsas, não é verdadeiro que a primeira seja menos verossímil do que a segunda, e não é verdadeiro que a segunda seja menos verossímil do que a primeira. Portanto, o conceito de verossimilitude/verossimilhança não pode ser usado como uma medida para a comparação de duas teorias reais a respeito da verdade relativa ou do conteúdo de falsidade delas. A modificação oferecida por Newton-Smith também não é satisfatória. OLCZYK, S. On Newton-Smith's Concept of Verisimilitude. Conceptus XXIII, 1989. p. 67-76).

45 BERNSTEIN, 0p. cit, p. 60.

46 CURTIS, Op. cit, p. 95; NEWTON-SMITH, 1981, p. 4-8, 266-7.

47 SIEGEL, H. What is the Question Concerning the Rationality of Science. Philosophy of Science 52. 1985, p. 517-37.

48 LAUDAN, L. Science and Values: The Aims of Science and Their Role in Scientific Debate. Los Angeles: University of California Press, 1984. p. $39-41$.

49 Ibid., p. 50-62.

50 LAUDAN, L. Progress or Rationality? The Prospects for Normative Naturalism. American Philosophical Quarterly 24, 1987. p. $19-31$.

Cf. DOPPELT, G. Relativism and the Reticulated Model of Scientific Rationality. Synthese 69, 1986. p. 225-252.

SIEGEL, H. Laudan's Normative Naturalism. Studies in History and Philosophy of Science 21, 1990. P. 295-313.

STUMP, D. Fallibilism, Naturalism and the Traditional Requirements for Knowledge. Studies in History and Philosophy of Science 22, 1991. p. 451-469. Na percepção Siegel e Gerald Doppelt, a afirmação de Laudan de que as metas científicas devem ser não utópicas e enraizadas nas realidades da prática científica introduz uma força prescritiva que ultrapassa seu naturalismo (DOPPELT, Op. cit, 1986, p. 231; SIEGEL, Op. cit, 1990, p. 310-2). Laudan não se afeta por esse tipo de crítica. Ele aponta que a justificação é sempre a especificação de certas ações relativas a um fim (ou a fins). Assim, na visão de Laudan, a justificação epistêmica, se tem algum sentido, é um caso de racionalidade instrumental, de modo que não há duas formas exclusivas de racionalidade, a saber: a instrumental e a epistêmica alegadas como fora do continuum meios-fins (LAUDAN, L. Aim-less Epistemology? Studies in History and Philosophy of Science 21, 1990. p. 315-322).

51 LACEY, Hugh. Rationality of Science. In: MARGOLIS, J., KRAUSZ, M., BURIAN, R. M. (Ed.) Rationality, Relativism and the Human Sciences. Dordrecht: Martinus Nijhoff Publ., 1986. p. 127-49.

52 Cf. POPPER, Op. cit, 1972, p. 52-60.

53 A diferença entre a posição intermediária e a dogmática pode ser expressa da seguinte maneira. Enquanto um defensor da posição dogmática procura por padrões permanentes de racionalidade, um adepto da posição intermediária busca padrões de racionalidade permanente. A primeira deve se declarar um imutabilista, ou seja, não pode permitir revoluções metodológicas na ciência, enquanto a segunda pode acolher essas rupturas de bom grado (CURTIS, Op. cit,1989, p. 95-6).

54 Toulmin encontra essas bases em problemas enfrentados por pessoas de todas as culturas (1972, p. 498). Newton-Smith considera a aceitação (ou não) dos ditames da razão e os liga à sobrevivência: sem ajustar a nossa rede de crenças com base na experiência e ditames da razão, não devemos sobreviver por muito tempo. (NEWTON-SMITH, Op. cit,1981, p. 254-5). Siegel se refere aos compromissos da ciência à evidência como o fundamento de sua racionalidade (SIEGEL, 1985, p. 524-36). H. Meynell admite que há faculdades mentais transsociais envolvidas em autotranscendência cognitiva que são as bases para a verdade dos julgamentos e a validade dos argumentos (MEYNELL, H. On the Limits of the Sociology of Knowledge. Social Studies of Science 7, 1977. p. 489-500). 

metodológico tradicional afirmou, ou que têm de avaliar a ciência e criticá-la por ser irracional, como [disse] Lakatos.

57 A perspectiva dele se aproxima da abordagem de Polanyi que será apresentada na seção que conclui este artigo.

58 FEYERABEND, P. K. Science in a Free Society. London: New Left Books, 1978. p. 24.

59 Ibid., p. 25

60 Ibid., p. 26

61 Ibid., p. 164-5.

62 FEYERABEND, 0p. cit, 1988, p. 243-4, 250.

63 TOULMIN, Op. cit, p. 485, 495

64 Ibid., p. 484.

65 FEYERABEND, Op. cit, 1978, p. 27-8.

66 McGUIRE, Op. cit, p. 145; ver também KUHN, T. S. The Structure of Scientific Revolutions. 2. ed. Chicago: The University of Chicago Press, 1970. p. 8-9.

67 Cf. BERNSTEIN, Op. cit, p. 23; FEYERABEND, Op. cit, p. 152-6; MCMULLIN, E. Values in Science. In: KLEMKE, D., HOLLINGER, R., KLINE, A. D. (Ed.). Introductory Readings in the Philosophy of Science, Buffalo: Prometheus Books, 1988. p. 349-371.

68 KUNH, Op. cit, p. 44.

69 Kuhn esclarece, por exemplo, que seu termo "matriz disciplinar" substitui o termo padrão "teoria". Além de generalizações verbais e simbólicas, com as quais as teorias são tradicionalmente identificadas, uma matriz disciplinar contém exemplares, quer dizer, soluções de problemas exemplares que ensinam os cientistas como entender e usar uma dada teoria. Cf. KUHN, T. S. Objectivity, Value Judgment, and Theory Choice. In: KUHN, T. S. The Essential Tension. Selected Studies in Scientific Tradition and Change, Chicago: The University of Chicago Press, 1977b. p. 320-339.

70 BERNSTEIN, Op. cit, p. 63.

71 KUHN, Op. cit, 1970, p. 42.

72 Na visão dos neopositivistas, a necessidade dos valores na descrição da atividade científica não era reconhecida porque eles baniram a prática da ciência do campo dos estudos filosóficos. Ademais, eles estavam decididos a excluir os valores da linguagem da ciência, porque juízos de valor não podem ser expressos em enunciados.

73 LEWIS, C. I. An Analysis of Knowledge and Valuation, La Salle, III: The Open Court, 1946.

74 RUDNER, R. The Scientist Qua Scientist Makes Value Judgments. In: KLEMKE, D, HOLLINGER, R. KLINE, A. D. (Ed.). Introductory Readings in the Philosophy of Science. Buffalo: Prometheus Books, 1988. p. 327-333.

75 A maioria dos autores parece não traçar distinção entre os valores e os objetivos do empreendimento científico (cf. MCMULLIN, E. Rationality and Paradigm Change in Science. In: HORWICH, P. (Ed.). World Changes. Thomas Kuhn and the Nature of Science. Cambridge: The MIT Press, 1993. p. 67.

76 KUHN, Op. cit, 1970, p. 199; KUHN, T. S. Rationality and Theory Choice. The Journal of Philosophy LXXX, p. 1983. p. 563-570; KUHN, Op. cit, 1977b; MCMULLIN, Op. cit, 1988; 1993; RESCHER, N. A System of Pragmatic Idealism, v. 1: The Validity of Values: A Normative Theory of Evaluative Rationality, Princeton, N.J.: Princeton University Press, 1991; ver também BERNSTEIN, Op. cit,1983, p. 54-7.

77 RESCHER, 0p. cit,1991, p. 110.

78 Cf. MCMULLIN, Op. cit,1988, p. 351; 1993, p. 69.

79 MCMULLIN, Op. cit,1988, p. 364; RUDNER, Op. cit,1988, p. 328, 330.

80 KUHN, T. S. Logic and Discovery or Psychology of Research. In: KUHN, T. S. The Essential Tension. Selected Studies in Scientific Tradition and Change, Chicago: The University of Chicago Press, 1977b. p. 330-4; MCMULLIN, Op. cit, 1988, p. 368.

81 Consoante Kuhn, precisão, escopo e fecundidade são "atributos permanentes da ciência", embora suas aplicações, os pesos relativos a eles imputados, e, de fato, seus conteúdos se modifiquem na história da ciência (KUHN, Op. cit, 1977b, p. 335). Isso significa que não são absolutos, mas apenas relativamente mais estáveis do que as teorias. Para McMullin, precisão predicativa e poder explanatório são valores (metas) definitivos da ciência (1993, 64-9). Ironicamente, Laudan e Shapere, que acusaram Kuhn de subjetivista, abraçam, agora, uma posição ainda mais relativista ou naturalista, declarando que os valores mudam no curso da história da ciência (LAUDAN, L. Science and Values: The Aims of Science and Their Role in Scientific Debate. Los Angeles: University of California Press, 1984. p. 62-4; SHAPERE, D. Reason and the Search for Knowledge, Dordrecht: Reidel, 1984. p. XXX, 208-14, 251).

82 Do ponto de vista desse critério particular do globalismo, a concepção de Lakatos deveria ser inclú́da nisso. Entretanto, seu uso da concepção de programas de pesquisa científica, sua insistência em separar o que é interno (puramente racional) e o que é externo à história da ciência, e sua ideia de reconstrução racional da ciência, situa-o na abordagem metodológica descontextualizada e idealizada.

83 KUHN, Op. cit, 1970, p. 46.

84 Ibid., p. 112.

85 FEYERABEND, Op. cit, 1988, p. 260

86 HEMPEL, C.; OPPENHEIM, P. Studies in the Logic of Explanation. In: Philosophy of Science 15, 1948. p. 135-175

87 MITCHELL, S. Biological Complexity and Integrative Pluralism. Cambridge: Cambridge University Press, 2003.

88 SALMON, W. Scientific Explanation and the Causal Structure of the World. Princeton: University of Princeton Press, 1984.

89 DOWE, P. Physical Causation. Cambridge: Cambridge University Press, 2000.

90 MACHAMER, P.; DARDEN, L.; CRAVER, C. Thinking about Mechanisms. In: Philosophy of Science 67 (1), 2000. p. 1-25. 
92 Tradicionalmente, a concepção de se fundar todas as ideias e todos os juízos (ou termos e sentenças) na experiência foi acompanhada no empirismo pela suposição de que a indução é o raciocínio que leva do conhecimento particular para o universal. A conjunção do indutivismo com o ideal da certeza gerou dificuldades bem conhecidas com relação à justificação da indução. No entanto, como mostram as versões contemporâneas do empirismo, nem 0 indutivismo, nem o ideal de certeza, são elementos indispensáveis do empirismo.

930 entendimento neopositivista sobre a linguagem que constitui o fundamento da ciência passou pelas fases bem conhecidas do psicologismo, fenomenalismo e fisicalismo. Os ideais da intersubjetividade dos dados empíricos e da unidade da ciência foram os critérios cruciais preservados durante essas mudanças.

94 GLYMOUR, C. Realism and the Nature of Theories. In: SALOMON, M. H. et al. Introduction to the Philosophy of Science. A Text by Members of the Department of the History and Philosophy of Science of the University of Pittsburgh. Englewood Cliffs, NJ: Prentice-Hall, 1992. p. 114.

95 SHAPERE, Op. cit, 1969, p. 117.

96 Os críticos do empirismo lógico reconheceram que um de seus pressupostos era a ideia de uma profunda simetria entre verdades empíricas e analíticas, entre provas na lógica ou na matemática e a verificação das proposições empíricas por meio de observações (BAKER, G. Wittgenstein, Frege and the Vienna Circle. Oxford: Basil Blackwell, 1988. p. 223). E mesmo quando os empiristas estavam cientes de que enunciados (teóricos) poderiam ser justificados logicamente somente mediante outros enunciados, de certo modo eles acreditavam que a experiência perceptual proporcionava um tipo de justificação para enunciados observacionais (POPPER, 1959, p. 43), que são "derivados" da experiência (BAKER, Op. cit, p. 169), que há um "nexo lógico direto" entre evidência e teoria (MCMULLIN, Op. cit, 1988, p. 369).

97 PUTNAM, H. What Theories Are Not. In: KLEMKE, D.; HOLLINGER, R.; KLINE, A. D. (Ed.). Introductory Readings in the Philosophy of Science. Buffalo: Prometheus Books, 1988. p. 178-183.

98 QUINE, 0p. cit, 1953, p. 41

99 RAMBERG, B. T. Donald Davidson's Philosophy of Language. Oxford: Basil Blackwell, 1989. p. 11.

100 KOLAKOWSKI, L. Religion: If There Is no God - On God, the Devil, Sin and other Worries of the so-called Philosophy of Religion, London: Fontana Paperbacks, 1982. p. 163. HACKING, I. Representing and Intervening: Introductory Topics in the Philosophy of Natural Science. Cambridge: Cambridge University Press, 1983. p. 154-9. Ibid., 1983, p. 220-1, 230 .

KUHN T. S. "Afterwords". In: HORWITCH, P. (Ed.). World Changes. Thomas Kuhn and the Nature of Science. Cambridge, Mass: The MIT Press, 1993. p. 311-341; LENOIR, T. Practice, Reason, Context: The Dialogue between Theory and Experiment. Science in Context 2 (1988/1), p. 3-22; WISE, M. N. Mediations: Enlightenment Balancing Acts, or the Technologies of Rationalism. In: HORWICH, P. (Ed.). World Changes. Thomas Kuhn and the Nature of Science, Cambridge, Mass.: The MIT Press, p. 207-256.

LENOIR, Op. cit,1988, p. 6

117 WISE, Op. cit, 1993, p. 213-4, 244-5

118 Ibid., p. 248-9.

119 KUHN, Op. cit, 1993, p. 332.

120 HACKING, 0p. cit, 1983, p. 262-3.

121 FEYERABEND, P. K. Realism and the Historicity of Knowledge. In: The Journal of Philosophy, 86, 1989. p. 393-406

122 TOULMIN, 1972; HULL, D. L. Science as a Process: An Evolutionary Account of the Social and Conceptual Development of Science. Chicago: Chicago University Press, 1990; GIERE, R. N. Explaining Science: A Cognitive Approach. Chicago: The University of Chicago Press, 1988. Na verdade, a visão de Popper de que o desenvolvimento da ciência é um prolongamento da evolução biológica também pertence à abordagem naturalista. Essa parte de sua concepção, bem como outros modelos evolucionistas do crescimento da ciência não serão aqui considerados.

124 No primeiro caso, "se a teoria continua a oferecer confirmação para os sistemas em seu escopo original, entende-se isto como expandi-la de modo a abranger domínios mais largos de sistemas de fenômenos". Um exemplo frequentemente citado a esse respeito é a extensão da mecânica clássica de partículas à mecânica do corpo rígido (SUPPE, 0p. cit, 1977, p. 53). Esse caso se refere ao seguinte cenário do desenvolvimento da ciência: uma vez que uma teoria altamente confirmada é estabelecida, esta continua a ser aceita e pode ser estendida a um domínio mais amplo, de tal maneira que a teoria anterior e mais estreita é reduzida àquela. Na segunda situação, várias teorias discrepantes, cada uma gozando de altos níveis de confirmação, são 
incluídas em, ou reduzidas a, alguma teoria mais inclusiva (idem.). Em outras palavras, uma teoria antiga foi incorporada em uma teoria mais abrangente, junto com outras teorias existentes que se referiam a domínios relacionados. Ambos os tipos de relações entre teorias sucessoras são, geralmente, consideradas como dois tipos de redução teórica e usados para descrever o progresso científico. Os empiristas lógicos também consideraram uma terceira situação. Nesse caso, certos desenvolvimentos (por exemplo, avanços tecnológicos que aprimoram drasticamente a precisão da observação e da mensuração) mostram que uma teoria existente, amplamente aceita como confirmada, é predicativamente inadequada, pelo menos em parte, e, então, seu grau de confirmação é derrubado. A revolução copernicana, às vezes, é apresentada como um exemplo disso (idem.). Tais casos poderiam ser interpretados como instâncias de desconfirmação de teorias existentes levando à sua exclusão da ciência. Para os empiristas lógicos, porém, são casos de aprimoramento de teorias existentes, substituindo-as por suas novas versões porque os avanços tecnológicos, que permitem observar novos fenômenos ou conduzir mensurações mais precisas, exigem novas regras de correspondência. A mudança das regras de correspondência significa que uma nova teoria foi construída.

A existência desse fenômeno na ciência foi reconhecido muito antes por Polanyi $(1964$, p. 112, 151) e Ludwig Fleck.

KUHN, Op. cit, 1970, p. 266-71; KUHN, T. S. Rationality and Theory Choice. In: The Journal of Philosophy LXXX, p. 563-570.

KUHN, Op. cit, 1970, p. 150.

Ibid., p. 148-50.

FEYERABEND, Op. cit, 1978, p. 67; 1988, p. 218-26.

Ibid., p. 66.

Ibid., p. 68.

Ibid. p. 69 .

Ibid., p. 70.

BERNSTEIN, 0p. cit, p. 92.

Ibid., p. 85-6.

BERNSTEIN, Op. cit, p. 92.

Cf. RESCHER, N. A System of Pragmatic Idealism, volume. III. Metaphilosophical Inquiries. Princeton, N.J.: Princeton University Press, 1994; WACHBROIT, R. Progress: Metaphysical and Otherwise. Philosophy of Science 53. 1986. p. 354-71. Risto Hilpinen oferece uma classificação similar das teorias filosóficas progresso cognitivo (científico). Existem teorias de acumulação, de acordo com as quais o progresso ocorre quando mais e mais verdades que formam a Verdade são incluídas no conhecimento científico; teorias de convergência vêem o progresso como aproximação da verdade; e as teorias pragmáticas pressupõem "que o propósito da investigação é proporcionar respostas satisfatórias à certas questões" (HILPINEN, R. On the Characterization of Cognitive Progress. Reports from the Department of Theoretical Philosophy no. 16. Turku: University of Turku, 1986. p. 2-7).

POPPER, Op. cit, 1972, p. 118-9, 243-4.

139 LAKATOS, Op. cit, 1978, p. 87-90, 118.

LAKATOS, Op. cit, 1978, p. 69-72, 76; ver também ZAHAR, E. Einstein's Revolution: A Study in Heuristic. La Salle, Illinois: Open Court, 1989. p. 23.

LAKATOS, Op. cit, 1978, p. 31-2, 69 .

POPPER, Op. cit, 1972; LAKATOS, Op. cit, 1978, p. 113-4.

GIERE, Op. cit, 1988, p. 34.

KUHN, Op. cit, 1970, p.12.

CALLEBAUT, 0p. cit, 1993, p. 56-9.

KUHN, Op. cit, 1970, p. 185.

KUHN, Op. cit, 1977a, p. 325; ver também MULKAY, M., GILBERT, N. Theory Choice [1984]. In: MULKAY, M., Sociology of Science. A Sociological Pilgrimage. Philadelphia: Open University Press, 1991. p. 133.

KUHN, 1970a, p. 204. Falando objetivamente, no núcleo das revoluções científicas há uma mudança de categorias taxonômicas que nos permitem descrever e generalizar, porque as revoluções "alteram o conhecimento da natureza que é intrínseca à linguagem em si mesma". Essa mudança também tem uma base psicológica, a saber, "uma mudança na noção do que é similar ao quê, e do que é diferente" (KUHN, T. S. What Are Scientific Revolutions? In: KRÜGER, L.; DASTON, L. J.; HEIDELBERGER, M. (Ed.) The Probabilistic Revolution, v. 1: Ideas in History. Cambridge, Mass: The MIT Press, 1987. p. 7-22.

GIERE, Op. cit, 1988, p. 1.

FEYERABEND, Op. cit, 1987, p. 118.

Os modelos de desenvolvimento científico que procuram padrões reprodutíveis de desenvolvimento são inspirados pelo modelo dedutivo nomológico da explicação científica aplicável também, sob a perspectiva de Carl Hempel, aos processos históricos. 0 modelo requer 0 estabelecimento de uma regularidade universal sob a qual todo evento explicado, por exemplo, uma mudança científica, pode ser subsumida. A afinidade é a razão pela qual chamamos os modelos examinados de "modelos nomológicos de mudança científica". Para uma discussão mais ampla desse assunto, ver MARGOLIS, J. The Flux of History and the Flux of Science. Berkeley: University of California Press, 1993. p. 21-57.

ROUSE, J. Philosophy of Science and the Persistent Narratives of Modernity. Studies in History and Philosophy of Science 22, 1991. p. 141-62.

LAUDAN, Op. cit, 1984, p. 63.

Ibid., p. 50-62, 65 .

GINEV, D. Scientific Progress and the Hermeneutical Circle. Studies in History and Philosophy of Science 19, 1988. p. 39-395.

SHAPERE, Op. cit, 1984, p. XXIV, p. XXII-XXXVIII, 205-8, 251-4.

Cf. KUHN, Op. cit, 1980, p. 185.

FEYERABEND, 1987, p. 118. 
LAKATOS, Op. cit, 1978, p. 22; RADNITZKY, G. In Defense of Self-Applicable Critical Rationalism. In: RADNITZKY, G., BARTLEY, W. W. (Ed.) Evolutionary Epistemology, Rationality, and the Sociology of Knowledge III. La Salle, Illinois: Open Court, 1987. p. 279-312.

BARTLEY, W. W. Theories of Rationality. In: Radnitzky, G., Bartley, W. W. Evolutionary Epistemology, Rationality, and the Sociology of Knowledge. III. La Salle, Illinois: Open Court, 1987. p. 205-214.

RADNITZKY, Op. cit, 1987, p. 301-2.

BARTLEY, Op. cit, 1987, p. 211-4; RADNITZKY, Op. cit, 1987, p. 303.

MUSGRAVE, A. The Objectivism of Popper's Epistemology. In: SCHILPP, P. A. (Ed.). The Philosophy of Karl Newton-Smith Popper. La Salle, Illinois: Open Court, 1974. p. 560-599

Newton-Smith conclui sua análise crítica da concepção popperiana afirmando que Popper falhou ao estabelecer o que havia considerado ser os métodos da ciência (falsificação) enquanto um meio para o que tomou como sendo o fim da ciência (aumento da verossimilitude) (1981, p. 75). Gerard Radnitzky faz notar que o progresso cognitivo na ciência não pode ser alcançado somente pelo criticismo, porque sua função é apenas a eliminação do erro (1987, p. 288). 0 criticismo deve ser, portanto, suplementado pela criação de hipóteses científicas. E mais: de modo a preservar a ideia de progresso, Popper deve assumir que sua criação (diferentemente das mutações biológicas) não é uma variação cega. Esta deve ser progressiva; os cientistas devem oferecer hipóteses cada vez melhores. Há também um argumento crítico de Nicholas Rescher. 0 fato de que uma imagem da natureza seja a mais garantida [warranted] não significa que seja a melhor imagem. 0 que atingimos durante o desenvolvimento da ciência é apenas uma estimativa mais embasada da verdade, o que oferece uma garantia mais firme para as nossas declarações (RESCHER, N. The Limits of Science, Berkeley: University of California Press, 1984. p. 73-4).

Os adeptos de uma visão racionalista geralmente nos alertam do perigo de se substituir razões por causas.

KOLAKOWSKI, L. Looking for the Barbarians: The Illusions of Cultural Universalism. In: KOLAKOWSKI, L. Modernity on Endless Trial. Chicago: The University of Chicago Press, 1990. p. 14-31.

LEWIS, Op. cit, 1946, p. 1-23, 365-96; RESCHER, Op. cit, 1991, p. 81-92.

Por exemplo, a racionalidade da descoberta científica pode ser "localizada em algum lugar entre as estruturas do comportamento e as das proposições, nos hábitos, nas habilidades, nas atitudes e nos interesses carregados de valor [value-laden] que constituem a forma de vida do cientista, e na situação do campo que ele herda de seus predecessores (KISIEL, T. The Rationality of Scientific Discovery. In: GERAETS, Th. F. (Ed.) Rationality today. La rationalite aujourd'hui. Ottawa: University of Ottawa Press, 1979. p. 401-11.

KOLAKOWSKI, Op. cit, 1990, p. 193-7.

Ibid., p. 193.

Ibid., p. 175.

Cf. KISIEL, Op. cit, 1979, p. 402.

TOULMIN, Op. cit, 1972, p. 262.

LONGINO, H. Multiplying Subjects and the Diffusion of Power. In: The Journal of Philosophy LXXXVIII, 1991/11. p. 666-674.

LAKATOS, Op. cit, 1978, p. 114-7.

POLANYI, Op. cit, 1964, p. 264.

Ibid., p. 15-8, 134-5, 262-72, 294-7, 311, 323; POLANYI, M.; PROSCH, H. Meaning, Chicago: The University of Chicago Press, 1975. p. 29.

POLANYI, Op. cit, p. 264.

Ibid., p. 268.

Ibid., p. 311.

Ibid., p. 64-5, 300.

Ibid., p. 308.

Ibid., p. 134-6.

Ibid., p. XIII.

Ibid., p. 309.

Ibid., p. 183-4.

Ibid., p. 63.

Ibid., p. 276.

Ibid., p. 164.

TOULMIN, Op. cit, 1972, p. 158.

KUHN, Op. cit, 1993, p. 329.

KUHN, Op. cit, 1970a, p. 200; ver também LONGINO, Op. cit, 1991, p. 669-70.

KUHN, 1993, p. 328.

Ibid., p. 328.

Concordamos com Keith Jones (JONES, K. Is Kuhn a Sociologist? In: The British Journal for the Philosophy of Science 37, 1986. p. 443-452), embora seja por diferentes razões: as análises de Kuhn podem ser chamadas, na melhor das hipóteses, de psicologia social.

KUNH, Op. cit,1970a, p. 200.

KUHN, Op. cit,1993, p. 329. 
198 Ibid. p. 330.

199 Cf. LONGINO, Op. cit, 1991, p. 667-9.

200 KUHN, Op. cit, 1970a, p. 5, 24.

201 Ibid., p. 23-42.

202 LONGINO, Op. cit,1991, p. 670.

203 Ibid. p. 670.

204 Ver: BERNSTEIN, Op. cit, 1983, p. 74. e WARTOFSKY, Op. cit, 1979, p. 133-4 em referência a Kuhn e Lakatos; MCMULLIN, Op. cit,1979, p. 630 em referência a Laudan.

205 BERNSTEIN, Op. cit, p. 68.

206 Para uma discussão mais ampla sobre essas questões, ver McGUIRE, J.; TUCHANSKA, B. Science Unfettered: A Philosophical Study in Sociohistorical Ontology. Athens, Ohio: Ohio University Press, 2000. p. 224-72. Para uma discussão clássica sobre a historicidade, ver GADAMER, H.-G. Truth and Method. New York: Crossroad, 1994.

[Recebido em Maio de 2013. Aprovado para publicação em Julho de 2013] 